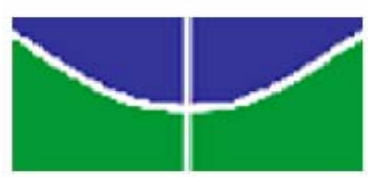

\begin{abstract}
UNIVERSIDADE DE BRASÍLIA
INSTITUTO DE CIÊNCIAS HUMANAS

DEPARTAMENTO DE SERVIÇO SOCIAL
\end{abstract}

Thaís Kristosch Imperatori

A COMPREENSÃO DE CUIDADORAS SOBRE O CUIDADO DE FAMILIARES IDOSOS COM DOENÇA DE ALZHEIMER

Brasília (DF), dezembro de 2007. 
Thaís Kristosch Imperatori

\title{
A COMPREENSÃO DE CUIDADORAS SOBRE O CUIDADO DE FAMILIARES IDOSOS COM DOENÇA DE ALZHEIMER
}

\author{
Monografia apresentada ao Departamento \\ de Serviço Social para obtenção do \\ diploma de graduação em Serviço Social, \\ sob orientação da Prof. ${ }^{a}$ Dra. Debora Diniz.
}

Brasília (DF), dezembro de 2007. 
Dedico esta monografia a meus pais pelo carinho e apoio. 


\section{Agradecimentos}

Agradeço a Deus pelos milagres do meu cotidiano.

À minha orientadora, professora Debora Diniz, pelo apoio, ensinamentos e reflexões que possibilitaram a realização desta pesquisa.

À professora Rosa Helena Stein e ao assistente social Cristiano Guedes pela disponibilidade com que aceitaram participar desta banca de defesa.

Aos professores do Departamento de Serviço Social, de modo especial às professoras Denise Bomtempo Birche de Carvalho e Nair Heloísa Bicalho de Sousa pelo carinho e todas as oportunidades durante minha graduação.

Aos funcionários do Departamento de Serviço Social pela atenção e prontidão em resolver problemas.

À assistente social Juliana Queiroga, minha supervisora de estágio no Centro de Medicina do Idoso (CMI), pela dedicação e por tanto contribuir com minha formação profissional.

À sra. Cleide Faria, por ser um exemplo de perseverança e sabedoria e por compartilhar comigo sua experiência.

A todos os profissionais do CMI que colaboraram comigo para a realização desta pesquisa, especialmente ao Dr. Renato Maia, pela confiança, e a Maristela, Luciana, Vera, Dante, Sueli e Mirian.

A todos os meus amigos e amigas, de modo especial aqueles que fizeram parte da minha graduação, e ao meu namorado.

Às colegas do Programa de Educação Tutorial (PET) por me ensinarem a trabalhar em grupo e respeitar opiniões diferentes.

A todas as cuidadoras que participaram desta pesquisa pelo exemplo e lição de vida.

Enfim, agradeço a todas as pessoas que, de alguma maneira, me ajudaram a chegar até aqui. 
"O tempo que muda tudo, muda também os nossos humores.

Cada idade tem seus prazeres, seu espírito e seus costumes" Nicolas Blileau 


\section{Resumo}

A população brasileira está envelhecendo e, com isso, novas demandas surgem para o Estado, a sociedade e a família, de forma particular no âmbito da saúde. Um importante problema de saúde da população idosa são as demências, especialmente a Doença de Alzheimer, que gera gradativa perda da independência e autonomia do idoso, e conseqüentemente, grande impacto no sistema familiar e a necessidade de alguém para assumir os cuidados. A presente pesquisa analisa a experiência do serviço do Centro de Medicina do Idoso do Hospital Universitário de Brasília e tem o objetivo de compreender como as cuidadoras de idosos com Doença de Alzheimer participam do tratamento dos idosos, realizam os cuidados e quais informações elas têm sobre a doença. Para tanto foi utilizada metodologia qualitativa para coleta, registro e análise dos dados, sendo realizadas entrevistas semi-estruturadas com 20 cuidadoras. Os resultados mostraram que as cuidadoras compreendem o caráter crônico e progressivo e que o cuidado é realizado a partir de diversas atividades, que incluem o cuidado restrito a doença, como dar medicação, realizar exames e ir a consultas, e fatores subjetivos, afetivos e emocionais, dentre eles, dar carinho, amor, atenção ao paciente. Destaca-se ainda que embora a literatura aponte que o cuidado seja prestado pela família, a tarefa de cuidar é centralizada na figura de uma cuidadora, que pode ou não contar com a colaboração de outros cuidadores ou cuidadoras.

Palavras-chaves: Envelhecimento; Doença de Alzheimer; Família; Cuidado; Cuidadora 


\section{Lista de tabelas}

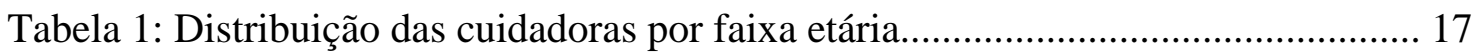

Tabela 2: Distribuição das cuidadoras por escolaridade................................................ 17

Tabela 3: Distribuição das cuidadoras pelo local de moradia....................................... 18

Tabela 4: Distribuição das cuidadoras pelo parentesco com o idoso

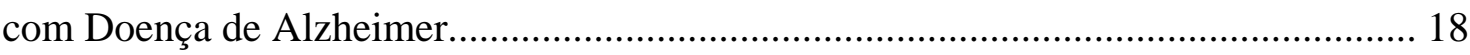

Tabela 5: Distribuição dos idosos com Doença de Alzheimer pela faixa etária............ 19 


\section{Sumário}

Introdução.

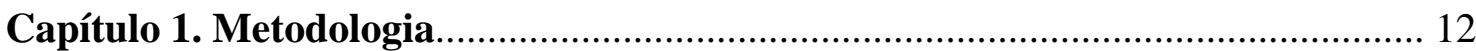

1.1. Estratégias de coleta de dados.................................................................... 13

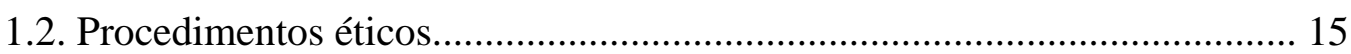

1.3. Plano de análise de dados........................................................................ 16

1.4. Perfil das participantes.......................................................................... 17

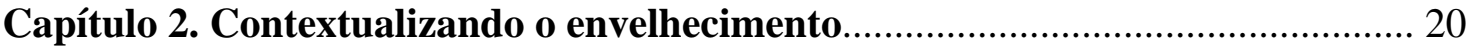

2.1. Definições de envelhecimento e velhice.................................................. 20

2.2. A realidade dos idosos brasileiros............................................................. 24

Capítulo 3. O idoso dependente e o cuidado na família....................................... 29

3.1. Articulando fragilidade, autonomia e dependência.................................... 29

3.2. Demência: problema de saúde do idoso..................................................... 33

3.3. Família como fonte de cuidados.............................................................. 34

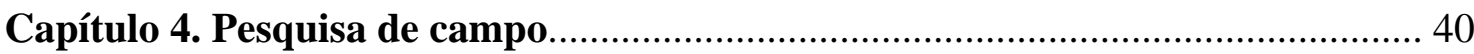

4.1. Início do tratamento e compreensão sobre Doença de Alzheimer.............. 40

4.2. Relacionamento entre cuidadora e idoso: Por que cuidar?.......................... 44

4.3. Rotina e significados do cuidar.................................................................. 47

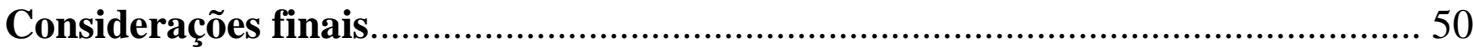

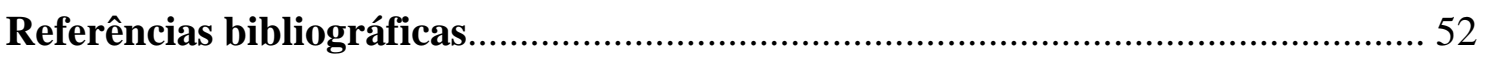

\section{Anexos}

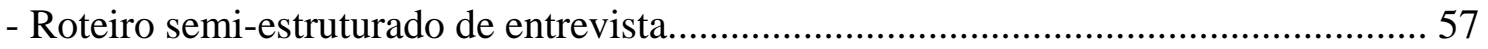

- Autorização do Centro de Medicina do Idoso para realização da pesquisa................. 59 


\section{Introdução}

O Brasil está envelhecendo. Dados do IBGE mostram que a proporção de idosos na população brasileira é cada vez maior. Se em 1940 representava 4\% da população, no ano 2000 chegou a 8,6\%, e estimativas apontam que em 2020 a população idosa chegará a 14\% dos brasileiros (BELTRÃO; CAMARANO; KANSO, 2004). Essa nova realidade demográfica já apresenta vários desafios para a sociedade e o Estado. Dentre eles, encontram-se novas demandas para a saúde pública, decorrentes do aumento da freqüência de doenças próprias do processo de envelhecimento.

Embora envelhecer não represente necessariamente a existência de enfermidades, nesse momento da vida há uma maior ocorrência de doenças crônicodegenerativas, dentre elas as demências e, em especial a Doença de Alzheimer. A demência é uma síndrome decorrente de alterações cerebrais, com natureza crônica e progressiva que modifica funções cognitivas como memória, atenção, aprendizado, pensamento, orientação, compreensão, cálculo, linguagem e julgamento, e que interfere em atividades cotidianas, por exemplo, higiene pessoal, vestir-se, alimentação e atividades fisiológicas (BRASIL, 2002). Dados epidemiológicos estimam que mais de 15 milhões de pessoas sejam afetadas pela Doença de Alzheimer em todo o mundo, e sua prevalência vem aumentando de forma significativa. As demências, porém, não se restringem ao aspecto biológico, mas também têm repercussões na economia, política, sociedade e cultura, e afetam de modo particular as família, que em geral assumem os cuidados.

Durante o estágio curricular realizado no Centro de Medicina do Idoso do Hospital Universitário de Brasília (CMI), especializado no diagnóstico e tratamento de Doença de Alzheimer e demais demências, composto por uma equipe multiprofissional e interdisciplinar, foi observado que a maioria das cuidadoras de idosos era do sexo feminino, o que destaca a importância do compontente gênero na análise da atenção à saúde do idoso.

A presente pesquisa foi um estudo de caso, com metodologia qualitativa, realizada por meio de entrevistas semi-estruturadas com 20 cuidadoras que têm familiar idoso atendido no CMI, sendo o objetivo analisar como essas cuidadoras compreendem o cuidado de familiares idosos com Doença de Alzheimer. Destaca-se que já foram 
atendidos aproximadamente $830^{1}$ pacientes no serviço, dado que inclui pacientes que já foram a óbito, desistiram do tratamento, não apresentaram diagnóstico de demência, ou aderiram e continuaram o tratamento. Não foi possível identificar quantos pacientes possuem o diagnóstico de Doença de Alzheimer e nem quantos aderiram ao tratamento. No entanto, considera-se que o total de entrevistas é significativo porque possibilitou aprofundar as análises a partir dos objetivos propostos.

Percebe-se que a família é a principal fonte de apoio e cuidado a esses idosos dependentes, sendo esses cuidados prestados na figura da cuidadora. Essa atividade de cuidar acarreta diversas conseqüências para a cuidadora, como ônus físico e financeiro, sobrecarga, estresse, frustração, sentimentos de gratidão e bem-estar, e implica diversos tipos de necessidade para o idoso e para a própria família. Nesse sentido, a pesquisa foi orientada pela seguinte hipótese: as cuidadoras compreendem que o idoso com Doença de Alzheimer tem necessidades que vão além do aspecto biomédico restrito à doença, e por isso, o cuidado é realizado a partir da junção de tarefas centradas na doença, como dar a medicação apropriada, realizar exames e ir a consultas, e de aspectos subjetivos, afetivos e emocionais, como dar carinho e atenção ao idoso.

Trata-se de uma pesquisa importante para o Serviço Social. De acordo com Leonia Capaverde Bulla et al (2004) o trabalho do Serviço Social com familiares de pacientes com Doença de Alzheimer é fundamental porque possibilita o acesso a informações sobre a doença e formas de cuidado, e também viabiliza mudanças na dinâmica familiar. Esse apoio profissional é necessário, sobretudo, para a definição de estratégias de atenção à saúde do idoso.

A monografia está estruturada em cinco capítulos. O primeiro capítulo visa a apresentar a metodologia e os procedimentos realizados na pesquisa. Trata-se de um estudo de caso realizado no Centro de Medicina do Idoso (CMI), com metodologia qualitativa para coleta, registro e análise dos dados. Também é apresentado o perfil das 20 cuidadoras entrevistadas.

No segundo capítulo é contextualizado o envelhecimento como realidade mundial. Primeiramente é feito um debate teórico sobre definições de velhice e

\footnotetext{
${ }^{1}$ Dado estimado a partir de informações obtidas no serviço.
} 
envelhecimento, sendo dada ênfase à chamada biomedicalização da velhice e a relação entre velhice e doença. Em seguida o capítulo trata da realidade dos idosos brasileiros a partir de dados estatísticos e do processo histórico de formulação de políticas para a população idosa.

A realidade dos idosos dependentes é tematizada no terceiro capítulo, no qual são articulados os conceitos de fragilidade, autonomia e dependência, e é discutida a idéia de normalidade. No mesmo capítulo é apresentado o conceito de demência e suas implicações para a família, compreendida como principal fonte de cuidados.

No quarto capítulo são debatidos os principais dados e resultados da pesquisa de campo. As evidências apontam que a maioria das cuidadoras tem uma visão ampliada de cuidado e das necessidades dos idosos com Doença de Alzheimer, que vai além de dar as medicações e fazer acompanhamento médico freqüentemente, e inclui dar carinho, amor, atenção, cuidar do ambiente físico, evitar brigas, dentre outros. As cuidadoras destacam a importância desses aspectos subjetivos tanto para a qualidade de vida dos familiares cuidados como para uma possível recuperação da saúde.

Por fim, o último capítulo apresenta as conclusões gerais da pesquisa e aponta propostas para futuras pesquisas a partir de questões emergentes do trabalho de campo e que são diretamente relacionados com o cuidado a idosos dependentes. Em anexo estão o questionário semi-estruturado utilizado para as entrevistas com as cuidadoras e a autorização do diretor do CMI para a realização da pesquisa. 


\section{Capítulo 1 \\ Metodologia}

O interesse pela temática do envelhecimento é decorrente do estágio curricular realizado no Centro de Medicina do Idoso do Hospital Universitário de Brasília (CMI), um centro de referência no diagnóstico e tratamento das síndromes demenciais, especialmente da Doença de Alzheimer. A proposta do serviço é oferecer um atendimento multiprofissional e interdisciplinar (Medicina, Psicologia, Fisioterapeuta, Farmácia, Serviço Social, Terapia Ocupacional, Educação Física, Odontologia, Neuropsicologia) que atenda o idoso e também sua família. Para tanto, são realizadas consultas médicas e de outros profissionais, e reuniões com grupos com familiares visando orientá-los sobre os cuidados diários ao paciente.

O CMI está inserido na estrutura do Hospital Universitário de Brasília, criado em 1972 e vinculado inicialmente ao Instituto de Pensão e Aposentadoria dos Servidores do Estado (IPASE). Após a extinção do IPASE, o hospital foi incorporado ao Instituto Nacional de Assistência Médica da Previdência Social (INAMPS). Somente em 1990 a instituição recebeu o nome de Hospital Universitário de Brasília e se inseriu na Rede de Hospitais Universitários do Ministério da Educação, o que possibilitou a incorporação do caráter Hospital-Escola, ou seja, da articulação do tripé ensino, pesquisa e extensão em sua rotina. Além disso, inseriu-se o compromisso de formação de novos profissionais de saúde juntamente com o atendimento à população e o desenvolvimento de novas tecnologias.

A assistente social da equipe, como profissional de saúde, conforme propõe a Resolução CNS no 218, de 6 de março de 1997, atua nos aspectos sociais do processo de adoecimento e promoção da saúde. Neste sentido, dentre outras atividades, participa do processo de admissão de novos pacientes ao serviço; realiza acompanhamento social por meio de contatos telefônicos, entrevistas individuais, reuniões com familiares; e também desenvolve atendimento domiciliar com demais profissionais para pacientes fragilizados e em situação de risco social. Além disso, participa de reuniões de equipe para estudo e discussão de casos nas quais são traçadas as estratégias de intervenção.

Ressalta-se que na adminissão de novos pacientes, que ocorre semanalmente, o idoso e seu familiar são atendidos pelos diferentes profissionais do CMI, de modo a possibilitar o contato com suas demandas médicas e biológicas, psicológicas e sociais. 
Neste sentido, o Serviço Social, por meio da avaliação social, identifica a situação sócioeconômica do idoso e sua família, o histórico de vida, e seu contexto familiar e rede de suporte social, assim como a necessidade de informações e encaminhamentos a benefícios previdenciários e de assistência social. Destaca-se que o Serviço Social tem pouco contato direto com os pacientes com demência, sendo sua ação direcionada aos familiares e cuidadores e cuidadoras.

Considerando que a proposta da pesquisa é analisar como as cuidadoras compreendem o cuidado a idosos com Doença de Alzheimer, esse projeto utilizou a estratégia do estudo de caso, que possibilitou fornecer explicações e elementos que marcam esse contexto. O estudo de caso também permite um aprofundamento na análise por se restringir a um grupo ou comunidade específica, e pela possiblidade de adaptação dos instrumentos e modificação da abordagem ao longo do processo de pesquisa, de acordo com a realidade encontrada (LAVILLE; DIONE, 1999). Neste sentido, optou-se por procedimentos qualitativos para coleta, registro, análise e interpretação dos dados. Trata-se de uma pesquisa interpretativa que ocorre em um cenário natural, sendo os fenômenos sociais analisados de forma complexa, interativa e abrangente (CRESWELL, 2007).

A pesquisa foi composta das seguintes etapas: 1. levantamento bibliográfico sobre envelhecimento, demências e cuidado a idosos dependentes; 2. elaboração do projeto de pesquisa; 3 . elaboração do instrumento de coleta de dados; 4. pré-teste do roteiro de entrevista semi-estruturada; 5. aplicação das entrevistas mediante gravação de voz; 6. transcrição das entrevistas, leitura e análise qualitativa dos dados levantados.

\subsection{Estratégias de coleta de dados}

Compreende-se por pesquisa qualitativa aquela que visa a entender determinada situação ou fenômeno social (CRESWELL, 2007). De acordo com Maria Cecília Minayo (1996), a pesquisa qualitativa se preocupa com um nível de realidade que não pode ser quantificado, em especial, nas Ciências Socias, por trabalhar com os significados, motivos, aspirações, crenças, valores e atitudes dos sujeitos envolvidos no processo de pesquisa. Para tanto, é observada a singularidade do fenômeno social e a complexidade da realidade, o que implica na necessidade de um uso teórico e técnico adequado. 
Para a elaboração da metodologia foram realizadas observações a grupos com familiares, atendimentos de diversos profissionais e entrevistas com cuidadoras e cuidadores de pacientes idosos com demência. A experiência do estágio curricular contribuiu para a escolha da metodologia, uma vez que já se conhecia a rotina do serviço, as principais demandas aos profissionais e o processo de trabalho. A escolha de pesquisar a compreensão das cuidadoras deu-se pelo fato de a maioria das pessoas que realizam cuidados no âmbito familiar ser do sexo feminino.

A coleta dos dados foi realizada por meio de entrevistas semi-estruturadas com as cuidadoras de familiares idosos com Doença de Alzheimer. Entende-se que essa técnica possibilitou acessar informações sobre a vivência das cuidadoras devido à combinação entre perguntas fechadas e abertas, nas quais as entrevistadas puderam discorrer sobre os temas propostos. Utilizou-se um guia de entrevista subdividido em três blocos: ${ }^{2}$ 1. perfil da cuidadora; 2. perfil do idoso; 3. informações sobre o cuidado. O guia de entrevista é compreendido como um roteiro que abrange a lista dos temas ou dos aspectos do tema que deverão ser abordados na entrevista, de modo a perguntar sobre os mesmos conteúdos em todas as entrevistas, sendo possível realizar perguntas complementares conforme a necessidade (COMBESSIE, 2004).

As entrevistas foram realizadas no próprio CMI, conforme seu horário de funcionamento. Optou-se por convidar para participarem da pesquisa cuidadoras que se encontravam na instituição para consultas médicas dos idosos ou outras atividades, como buscar receituários, relatórios médicos ou participar de atividades em grupo. Essa alternativa foi construída juntamente com a equipe do serviço, que argumentou as dificuldades de deslocamento das cuidadoras para a realização de entrevistas agendadas. A realização de entrevistas com essas cuidadoras também facilitou a análise dos prontuários, quando necessário e com caráter complementar à entrevista, uma vez que a sua maioria já se encontrava na unidade.

Foram estabelecidos os seguintes critérios para inclusão dos participantes:

- ter familiar atendido no Centro de Medicina do Idoso (CMI);

- ter familiar com diagnóstico de provável ou possível Doença de Alzheimer³

\footnotetext{
${ }^{2} \mathrm{O}$ guia de entrevista encontra-se em anexo.

3 É dado o diagnóstico de provável Doença de Alzheimer nos casos em que há um quadro clínico compatível com os sintomas da doença, baseando-se na exclusão de outras causas de demência por meio de exames laboratoriais e neuroimagem, como tomografia computadorizada e ressonância magnética. Os
} 
- residir na mesma residência que o familiar.

No primeiro contato com as cuidadoras, a entrevistadora era identificada como graduanda do curso de Serviço Social da Universidade de Brasília e eram apresentados os objetivos e procedimentos éticos da pesquisa. Em seguida as cuidadoras eram convidadas a colaborarem com a pesquisa por meio de entrevista com gravação de voz, sendo indagados, inicialmente, o diagnóstico do familiar idoso, se ele era atendido no CMI, e quem residia com o idoso. Se as respostas fossem compatíveis com os critérios de inclusão citados acima, a entrevista seguia de acordo com o roteiro proposto.

Destaca-se a dificuldade de saber quanto a amostra de 20 entrevistadas representa do total de pacientes atendidos no CMI. Foi obtida a informação de que, desde o funcionamento da unidade, já foram atendidos aproximadamente 830 idosos,

sendo que esse total inclui: ${ }^{4}$ pacientes que já foram a óbito, desistiram do tratamento, não apresentaram diagnóstico de demência, ou aderiram e continuaram o tratamento. Além disso, não foram encontradas informações sobre quantas cuidadoras com familiares atendidos no serviço possuem o perfil de inclusão na pesquisa. No entanto, para fins de avaliação qualitativa, o total de entrevistas é significativo porque possibilita aprofundar métodos mais exploratórios do que uma exploração estatística (COMBESSIE, 2004).

\subsection{Procedimentos éticos}

Devido ao curto espaço de tempo, o projeto de pesquisa não foi submetido a Comitê de Ética em Pesquisa. Entretanto, foram seguidas as orientações sugeridas na Resolução 196/96 do Conselho Nacional de Saúde, dentre elas o Consentimento livre e esclarecido. Trata-se da autorização do participante de pesquisa de participar, de livre vontade, na pesquisa, sendo esse informado sobre a natureza da pesquisa, objetivos, métodos e possíveis riscos. No presente projeto o consentimento das participantes foi oral.

Destaca-se que a realização da pesquisa não representou riscos nem prejuízos de ordem material, física ou moral as participantes. Além disso, ressalta-se que a pesquisa

casos de possível Doença de Alzheimer, por sua vez, incluem os pacientes que possuem variações na forma de apresentação ou evolução clínica e também em casos em que outras condições passíveis de produzir demência estejam presentes, sem serem consideradas responsáveis pelo quadro demencial (CARAMELLI; BARBOSA, 2002).

${ }^{4}$ Dado estimado a partir de informações obtidas no serviço. 
foi realizada com apoio dos profissionais e da coordenação do CMI, que também reconheceu não haver riscos a nenhuma das entrevistadas sendo garantido o anonimato e o sigilo das informações obtidas por meio das entrevistas. A apresentação dos dados obtidos na pesquisa e das narrativas das entrevistadas foi orientada pelo sigilo, sendo preservado o nome e informações pessoais das cuidadoras.

No que tange o retorno dos resultados da pesquisa aos participantes, está prevista a apresentação da pesquisa para a equipe de profissionais do CMI e para as participantes da pesquisa, assim como para quaisquer outros interessados no trabalho desenvolvido, além da entrega de uma cópia do trabalho final à biblioteca do serviço.

\subsection{Plano de análise de dados}

O processo de análise dos dados, iniciado após a realização das entrevistas, consite em extrair sentido dos dados e envolve preparar os dados para análise, conduzir análises diferentes, aprofundar o entendimento dos dados e fazer uma interpretação do significado dos dados (CRESWELL, 2007). É portanto, um processo constante de reflexão sobre os objetivos da pesquisa, a revisão bibliográfica, e os dados obtidos.

Todas as entrevistas foram transcritas pela pesquisadora de forma precisa, fiel e exaustiva, conforme propõe Jean-Claude de Combessie (2004), de modo a primar pela qualidade das informações e da análise dos dados. Foram utilizadas as técnicas do recentramento e retoque que permitem sintetizar, aperfeiçoar e tornar mais claras as informações encontradas de maneira dispersa nas entrevistas. Essa técnica facilitou o manuseio das informações e a análise dos dados a partir das evidências encontradas.

As transcrições foram lidas na íntegra com o objetivo de selecionar, organizar e classificar os temas que apareceram com maior freqüência nas entrevistas e que poderiam se tornar evidências de pesquisa. Esse processo, chamado de codificação, permitiu organizar, padronizar e nomear fatos, eventos e relatos que aparecem nas entrevistas, posteriormente transformados em categorias analíticas e temáticas (CRESWELL, 2007). 


\subsection{Perfil das participantes}

A amostra de 20 cuidadoras participantes da pesquisa apresenta o seguinte perfil:

- Conforme a Tabela 1, as cuidadoras encontram-se na faixa etária entre 32 e 81 anos de idade, sendo que 8 (oito) delas estão entre 40 e 59 anos. Totalizaram 8 (oito) também as cuidadoras idosas acima de sessenta anos de idade, sendo que dessas apenas 1 (uma) com mais de oitenta anos.

\section{Tabela 1: Distribuição das cuidadoras por faixa etária}

\begin{tabular}{l|l}
\hline FAIXA ETÁRIA & TOTAL \\
\hline Menos de 39 anos & 4 \\
Entre 40 e 59 anos & 8 \\
Entre 60 e 69 anos & 3 \\
Entre 70 e 79 anos & 4 \\
Acima dos 80 anos & 1 \\
\hline Total & $\mathbf{2 0}$ \\
\hline
\end{tabular}

Fonte: Entrevistas com amostra de cuidadoras de idosos com Doença de Alzheimer atendidos no Centro de Medicina do Idoso, 2007.

- Em relação à escolaridade, 8 (oito) entrevistadas terminaram o Ensino Superior, 6 (seis) finalizaram o Ensino Médio, 3 (três) cuidadoras afirmaram ter concluído o curso de Magistério, que foi incluído na pesquisa como uma categoria específica, e 3 (três) estudaram o Ensino Fundamental ou Alfabetização, de acordo com a Tabela 2.

Tabela 2: Distribuição das cuidadoras por escolaridade

\begin{tabular}{l|l}
\hline ESCOLARIDADE & TOTAL \\
\hline Ensino Superior & 8 \\
Ensino Médio & 6 \\
Magistério & 3 \\
Ensino Fundamental ou Alfabetização & 3 \\
\hline Total & $\mathbf{2 0}$ \\
\hline
\end{tabular}

Fonte: Entrevistas com amostra de cuidadoras de idosos com Doença de Alzheimer atendidos no Centro de Medicina do Idoso, 2007.

- Quanto à ocupação e profissão, 13 (treze) cuidadoras afirmaram não estarem trabalhando fora do lar, sendo que, destas, 5 (cinco) são aposentadas, 3 (três) estão desempregadas e 5 (cinco) se denominaram donas de casa ou do lar. As demais 
cuidadoras têm as seguintes profissões: professora, bancária, arquiteta, jornalista, bibliotecária, nutricionista e enfermeira.

- A distribuição dos locais de residência é apresentada na Tabela 3:

Tabela 3: Distribuição das cuidadoras pelo local de moradia

\begin{tabular}{l|l}
\hline LOCAL DE RESIDÊNCIA & TOTAL \\
\hline Asa Sul & 3 \\
Asa Norte & 3 \\
Sobradinho & 3 \\
Taguatinga & 2 \\
Ceilândia & 2 \\
Lago Sul & 2 \\
Lago Norte & 2 \\
Santa Maria & 1 \\
Paranoá & 1 \\
Riacho Fundo & 1 \\
\hline Total & $\mathbf{2 0}$ \\
\hline
\end{tabular}

Fonte: Entrevistas com amostra de cuidadoras de idosos com Doença de Alzheimer atendidos no Centro de Medicina do Idoso, 2007.

- Sobre o estado civil, 12 (doze) entrevistas são casadas, 4 (quatro) são solteiras, 2 (duas) são separadas e 2 (duas) são viúvas.

- Quanto à religião, a maioria das cuidadoras são católicas, 12 (doze), seguidas das evangélicas, 6 (seis). Uma entrevistada afirmou ser espírita e uma disse não ter religião.

- A Tabela 4 mostra que as cuidadoras, em sua maioria, são filhas e esposas dos idosos com Doença de Alzheimer atendidos no CMI, sendo respectivamente 9 (nove) e 6 (seis) entrevistadas:

Tabela 4: Distribuição das cuidadoras pelo parentesco com o idoso com Doença de Alzheimer

\begin{tabular}{l|l}
\hline \multicolumn{1}{c|}{ PARENTESCO } & TOTAL \\
\hline Filha & 9 \\
Esposa & 6 \\
Nora & 2 \\
Neta & 2 \\
Sobrinha & 1 \\
\hline \multicolumn{1}{c|}{ Total } & $\mathbf{2 0}$ \\
\hline
\end{tabular}

Fonte: Entrevistas com amostra de cuidadoras de idosos com Doença de Alzheimer atendidos no Centro de Medicina do Idoso, 2007. 
Observa-se que os familiares cuidados correspondem a 12 (doze) mulheres e 8 (oito) homens, na faixa etária entre 67 e 91 anos, sendo as maiores concentrações entre 80 e 89 anos, 8 (oito), e entre 70 e 79 anos, 7 (sete) idosos, conforme a tabela abaixo.

Tabela 5: Distribuição dos idosos com Doença de Alzheimer pela faixa etária

\begin{tabular}{l|l}
\hline FAIXA ETÁRIA DOS PACIENTES & TOTAL \\
\hline Menos de 70 anos & 3 \\
Entre 70 e 79 anos & 7 \\
Entre 80 e 89 anos & 8 \\
Acima de 90 anos & 2 \\
\hline Total & $\mathbf{2 0}$ \\
\hline
\end{tabular}

Fonte: Entrevistas com amostra de cuidadoras de idosos com Doença de Alzheimer atendidos no Centro de Medicina do Idoso, 2007. 


\title{
Capítulo 2 \\ Contextualizando o envelhecimento
}

O envelhecimento é um processo que implica alterações orgânicas e biológicas e mudanças na relação do indivíduo com sua família e a sociedade em geral. Trata-se de um fenômeno complexo que acompanha todo o desenvolvimento humano e que é estudado por diversas áreas do conhecimento como ciências sociais, psicologia, educação, serviço social, medicina e enfermagem. Entretanto, apesar de esse tema ser muito discutido atualmente, ainda não há consenso sobre a definição do envelhecimento, assim como a de outros conceitos como velhice, idoso e terceira idade $^{5}$.

Nesse sentido, o presente capítulo tem o objetivo de apresentar e discutir definições sobre envelhecimento e velhice sob a ótica de diferentes autores, de modo a possibilitar a crítica sobre a relação entre envelhecimento e saúde. Para tanto, serão apresentadas inicialmente diferentes definições de velhice e a influência do modelo biomédico no envelhecimento. Por fim, é analisada a realidade dos idosos no Brasil e o processo de conquista de direitos no cenário brasileiro.

\subsection{Definições de envelhecimento e velhice}

O estudo do envelhecimento e da velhice propõe questões sobre o início da velhice e os fatores que a determinam. Questiona-se o que define uma pessoa como idosa, ou o que a faz ser considerada como tal. Renato Veras (2003) reflete sobre essas perguntas no seguinte trecho:

\begin{abstract}
Quando uma pessoa se torna velha? Aos 55, 60, 70 ou 75 anos? Nada flutua mais do que os limites da velhice em termos de complexidade fisiológica, psicológica e social. Uma pessoa é tão velha quanto as suas artérias, quanto seu cérebro, quanto seu coração, quanto seu moral ou quanto sua condição civil? Ou é a maneira pela qual outras pessoas passam a encarar as características que classificam as pessoas como velhas? (VERAS, 2003, p. 10).
\end{abstract}

Destaca-se que a velhice nessa concepção baseia-se na relação entre fatores fisiológicos, psicológicos e sociais. Simone de Beauvoir (1990) também afirma a

\footnotetext{
${ }^{5}$ Embora se saiba que há uma discussão conceitual sobre os termos para designar esse grupo etário, no presente trabalho não haverá diferenciação no uso dos termos velhice, idoso ou terceira idade, sendo esses utilizados para tratar das pessoas com 60 anos de idade ou mais, de acordo com o Estatuto do Idoso (BRASIL, 2003).
} 
influência de diversos fatores na velhice, o que a torna mais do que soma de alterações fisiológicas e interiores ao indivíduo e passa a incluir as relações sociais nas quais a pessoa está inserida e que a fazem se sentir idosa. Para além disso, há uma dimensão existencial baseada na relação entre indivíduo e tempo, e o mundo e sua própria história.

\begin{abstract}
Ela [a velhice] é um fenômeno biológico: o organismo do homem idoso apresenta certas singularidades. A velhice acarreta, ainda conseqüências psicológicas: certos comportamentos são considerados, com razão, como característicos da idade avançada. Como todas as situações humanas, a velhice tem uma dimensão existencial: modifica a relação do indivíduo com o tempo e, portanto, sua relação com o mundo e com sua própria história. Por outro lado, o homem não vive nunca em estado natura; na sua velhice, como em qualquer idade, seu estatuto lhe é imposto pela sociedade à qual pertence (BEAUVOIR, 1990, p. 15).
\end{abstract}

Também é visto que o envelhecimento é um processo, conforme sugere a Organização Pan-Americana de Saúde (OPAS):

\begin{abstract}
um processo seqüencial, individual, acumulativo, irreversível, universal, não patológico, de deterioração de um organismo maduro, próprio a todos os membros de uma espécie, de maneira que o tempo o torne menos capaz de fazer frente ao estresse do meio-ambiente e portanto, aumente sua possibilidade de morte (apud BRASIL, 2006, p. 8).
\end{abstract}

A definição da OPAS afirma que o envelhecimento é individual e cumulativo, ou seja, um processo que ocorre ao longo da vida de cada pessoa. Entender o envelhecimento como não-patológico significa compreender que envelhecer não significa potencialmente estar doente, porém, por outro lado, não se pode considerar que todas as alterações que ocorrem com a pessoa idosa são resultantes de seu envelhecimento natural. A definição também considera a possibilidade de que a partir do próprio envelhecimento o corpo se torne menos apto para fazer determinadas atividades. Assim, descobrir como envelhecer de uma forma saudável e como lidar com as limitações que possam ocorrer é um desafio para o contexto familiar e social (BRASIL, 2006).

De acordo com Iraci Gonçalves Guimarães (2005), a velhice é, de modo geral, associada a modificações no corpo, especialmente a sinais externos, como embranquecimento dos cabelos, surgimento de rugas, andar mais lento e redução das capacidades auditiva e visual. Entretanto, mesmo que o ser humano se torne mais frágil nesse período da vida, envelhecer não significa adoecer. ${ }^{6}$ Tais mudanças, próprias da velhice, podem ser fatores de exclusão: “as alterações, orgânicas, física e mental,

\footnotetext{
${ }^{6} \mathrm{O}$ conceito fragilidade será trabalhado no Capítulo 2.
} 
desencadeadas pelo envelhecimento, são fatores de exclusão à medida que restringem a capacidade para desenvolver atividades compatíveis com os princípios e valores adotados pela sociedade” (MOSCA FILHO, 2006, p. 152).

Marcelo Medeiros e Debora Diniz (2004), ao aproximarem a discussão sobre envelhecimento ao tema da deficiência, observam algumas limitações decorrentes do envelhecimento: a ausência de mudanças na organização da sociedade que poderiam atender a essa população; a interdependência e o cuidado como algo necessário em vários momentos da vida, e não somente em situações de deficiência e velhice; e a previsibilidade do envelhecimento como possibilidade de entender a deficiência em um contexto social e econômico.

Para Myriam Moraes Lins de Barros (2004), as classificações das fases da vida são influenciadas pelo processo histórico e pelas instituições e áreas do conhecimento desenvolvidas ao longo do tempo, assim como as definições de temporalidades para a escolaridade, o trabalho, o casamento e para a aposentadoria. Barros (2004) também observa a associação da juventude como idade-padrão da sociedade contemporânea, ou seja, o valor social da juventude e sua referência para estabelecimento da velhice.

\begin{abstract}
É com os olhos da juventude que se percebe a velhice. Ela é vista como um declínio e, sobretudo, como a imposibilidade de ser positivamente valorizado na medida em que já ultrapassou o ponto máximo do ciclo de vida, seja do ponto de vista da capacidade produtiva como trabalhador, seja do ponto de vista da capacidade física e psíquica com a perda gradual da capacidade do corpo e da mente (BARROS, 2004, p. 17).
\end{abstract}

Outra forma de se compreender o envelhecimento é pela chamada medicalização da velhice e do envelhecimento que trata do poder dado à Medicina tanto para explicar a velhice e o envelhecimento como para propor soluções em pesquisas e intervenções. De acordo com Anita Liberalesso Neri (2006), a influência desse modelo no estudo do envelhecimento foi construída historicamente, desde o surgimento e consolidação da Geriatria e da Gerontologia como campos de atuação profissional.

Neri (2006) observa algumas distorções do modelo biomédico relacionado ao envelhecimento: 1. supergeneralização: crença em que todos os idosos são doentes ou que a velhice é uma doença; 2. supersimplificação: crença em que o envelhecimento ocorre da mesma forma em todas as pessoas e tem os mesmos resultados; 3. reducionismo: crença em que o modelo biomédico consegue explicar de forma completa o envelhecimento; 4. ilusão pseudocientífica: crença em que todas as descobertas 
médicas e tecnológicas têm base científica; 5. ilusão sobre a imediaticidade da aplicação da pesquisa básica: crença de que os produtos de pesquisa e tecnologia direcionados para a velhice estão ao alcance de todos.

Percebe-se que os pontos criticados tratam especialmente da relação entre envelhecimento e doença. Entende-se saúde, conforme o conceito apresentado pela Organização Mundial da Saúde (OMS): “um estado completo de bem-estar físico, mental e social e não meramente como ausência de doenças ou sofrimentos” (ONU, 2003, p. 51), ou seja, não se restringe saúde à ocorrência ou não de uma determinada patologia. Outro aspecto questionado é a idéia de que o envelhecimento é um fenômeno uniforme para todas as pessoas, o que desconsidera a individualidade e o histórico de vida de cada um. Sérgio Costa (2006) afirma que a velhice não é um fenômeno etário, social e biológico experimentado da mesma forma em todos os indivíduos, ou seja, nem sempre a idade cronológica de dois indivíduos corresponde a mesma idade biológica.

Geraldine Alves dos Santos (2002), ao discutir a relação entre envelhecimento e doença, observa a importância de se compreender o que significa estar doente, já que várias vezes a saúde é tratada como padrão de normalidade das pessoas, boa aparência, ou ausência de doença. A existência de um padrão de normalidade é criticada por Irani Argimon e Clarissa Trentini (2006) que afirmam que diversas mudanças físicas dos idosos são próprias de seu envelhecimento, ou seja, algumas determinadas dificuldades de funcionamento dos órgãos são esperadas e admissíveis na velhice. Entretanto, a imprecisão da idéia de normalidade torna difícil o diagnóstico de doenças, especialmente as psiquiátricas.

Percebe-se, portanto, que as definições de envelhecimento englobam diferentes aspectos: biológicos, psicológicos, sociais e culturais, o que expressa um conceito multifatorial. Essa perspectiva possibilita entender que embora o envelhecimento seja uma realidade mundial, não ocorre de forma igual em todas as pessoas, e nem em todas as culturas e países. A relação entre envelhecimento e saúde pode ser questionada porque, apesar de existirem doenças específicas deste grupo etário, não é possível estabelecer que todos os idosos são ou serão doentes. 


\title{
2.2. A realidade dos idosos brasileiros
}

Dados sobre o envelhecimento populacional no Brasil mostram que a quantidade de pessoas com mais de 60 anos, em relação ao total da população nacional, subiu de 4\%, em 1940, para 8,6\% em 2000, totalizando 14,5 milhões de idosos. Estima-se que em 2020 a população idosa no Brasil chegará a 30,9 milhões de pessoas, representando 14\% da população brasileira (BELTRÃO; CAMARANO; KANSO, 2004). Também observa-se que a população idosa está envelhecendo, já que o número de idosos com mais de 80 anos representa $12,6 \%$ do total da população idosa (CAMARANO; KANSO; MELLO, 2004).

O aumento da população idosa é resultado de dois processos: a alta taxa de fecundidade nas décadas de 1950 e 1960 comparada à fecundidade atual e à redução da mortalidade da população idosa. A queda da taxa de fecundidade modificou a distribuição etária da população brasileira, e a redução da mortalidade levou ao aumento do tempo vivido pelos idosos (CAMARANO; KANSO; MELLO, 2004). Também é observada a heterogeneidade do segmento populacional chamado idoso, já que se trata de um grupo que abrange aproximadamente 30 anos, desde os 60 anos até pessoas na faixa de 90 anos. Assim,

\begin{abstract}
dadas as diferentes trajetórias de vida experimentadas pelos idosos, eles têm inserções distintas na vida social e econômica do país. A heterogeneidade do grupo de idosos, seja em termos etários ou socioeconômicos, traz também demandas diferenciadas, o que tem rebatimento na formulação de politicas públicas para o segmento (CAMARANO; KANSO; MELLO, 2004, p. 25).
\end{abstract}

Ana Amélia Camarano (1999) enfatiza a importância de se conceituar o termo idoso para a formulação de políticas públicas, e afirma que a idéia do envelhecimento, definido por aspectos biológicos, é um parâmetro que possui obstáculos pois “torna-se aparentemente simples, demandando apenas que se estabeleça a idade-limite que separa a velhice da não-velhice para separar os idosos dos não-idosos” (CAMARANO, 1999, p. 3). Portanto, para a autora, devem ser incluídos no conceito características culturais compartilhadas pelos indivíduos e a diferenciação de grupos, a partir de sexo e/ou nível educacional.

Indicadores sóciodemográficos mostram que a maior concentração da população idosa do Brasil encontra-se nas regiões Nordeste e Sudeste e nas áreas urbanas, seguindo o padrão de distribuição espacial da população brasileira. Também é observado que o envelhecimento representa uma questão de gênero, conseqüência da 
sobremortalidade masculina, o que resulta na predominância das mulheres entre os idosos, representando 55\% dessa população. Trata-se da chamada feminização da velhice (CAMARANO; KANSO; MELLO, 2004).

Percebe-se também que o envelhecimento populacional tem modificado os arranjos familiares da sociedade como um todo. Algumas dessas mudanças são a proporção de famílias com pelo menos um idoso, que subiu de 21,6\% em 1980, para 24,1\% em 2000, e o aumento da proporção de domicílios chefiados por idosos, de 17,7\% em 1980, para 20,9\% em 2000 (BELTRÃO; CAMARANO; KANSO, 2004).

De acordo com Maria Claudia Moura Borges (2006), mudanças no perfil etário da população brasileira e no perfil da população idosa têm levado à ampliação de discussões relacionada à população idosa e a políticas sociais voltadas para este segmento social, que passam a incluir toda a sociedade, visando redefinir espaços sociais e formas de melhorar as condições de vida dos idosos.

As preocupações sociais decorrentes do envelhecimento da população brasileira têm origem na década de 1960. Neste mesmo período surge um discurso científico sobre o envelhecimento e nasce o interesse de instituições e profissionais sobre o tema. As ações do Estado, porém, estavam restritas ao asilamento e direcionadas ao idoso pobre, carente, doente e marginalizado pela sociedade (LOBATO, 2006). Neidil Espinola da Costa, Jurilza Mendonça e Albamaria Abigalil (2002) afirmam que a questão do idoso no Brasil permaneceu, por muito tempo, articulada à saúde e à previdência social, sendo a aplicação de recursos financeiros em políticas para o idoso considerada como gasto desnecessário. Borges (2006) destaca alguns fatos marcantes para a história das políticas públicas direcionadas para a população idosa no Brasil:

- criação do Ministério da Previdência e Assistência Social, em 1976, quando começou a ser elaborada uma política voltada principalmente para os idosos aposentados e iniciaram-se estudos sobre a situação da velhice no Brasil, país considerado até então jovem;

- início de organização social de grupos de representantes de idosos em Ribeirão Preto e Catanduva, com os objetivos de lutar por uma revisão no valor das aposentadorias que muitas vezes não chegavam ao valor de um salário mínimo, e de trazer à tona a situação da população idosa como um todo; 
- realização da primeira Assembléia Nacional de Idosos, em 1982, em São Paulo, que reuniu 2.200 idosos representando 22 estados brasileiros e resultou na inclusão de alguns parágrafos na Constituição Federal de 1988 visando a melhoria da qualidade de vida dos idosos;

- criação do Conselho do Idoso e da Associação Nacional de Gerontologia, ampliando as áreas de atuação profissional junto aos idosos;

- criação da Política Nacional do Idoso (PNI) e do Estatuto do Idoso.

Alzira Teresa Garcia Lobato (2006) analisa outros momentos importantes para a velhice no Brasil, dentre eles a década de 1980, na qual foram criados programas governamentais que implementaram grupos e centros de convivência, e nãogovernamentais, como a organização de idosos em associações e a criação de programas de preparo para a aposentadoria. Em 1984 foi criado o primeiro Conselho Estadual do Idoso, em São Paulo, e em 1988 foram criados os Conselhos dos estados do Rio Grande do Sul e de Santa Catarina. Outro marco apresentado foi a criação das "Normas para funcionamento das casas geriátricas e asilos”, pelo Ministério da Saúde, em 1988, que demarcaram o interesse do governo em fiscalizar o atendimento a idosos nessas instituições.

A Constituição Federal de 1988, conhecida como constituição cidadã, legitimou direitos sociais e incoropou pela primeira vez a questão do idoso em uma legislação nacional. Essa legitimação foi resultado de lutas e reivindicações das associações e confederações dos aposentados (LOBATO, 2006). Destaca-se o artigo 230 que diz: “a família, a sociedade e o Estado têm o dever de amparar as pessoas idosas, assegurando sua participação na comunidade, defendendo sua dignidade e bem-estar e garantindolhes o direito à vida” (BRASIL, 2004, p. 130).

O artigo 203 da Constituição, por sua vez, pode ser considerado inovador por assegurar, no âmbito da assistência social, “a garantia de um salário mínimo de benefício mensal à pessoa portadora de deficiência e ao idoso que não possuir meios para prover sua própria manutenção ou tê-la provida por sua família” (BRASIL, 2004, p. 120). Esse benefício, Benefício de Prestação Continuada (BPC), foi regulamentado pela Lei Orgânica da Assistência Social (LOAS), Lei 8742/93, artigo 20. Posteriormente, por meio do Estatuto do Idoso (2003), a idade mínima para o idoso ter acesso ao benefício foi reduzida de setenta para 65 anos de idade. 
Para Borges (2006) é importante observar o contexto sociopolítico neoliberal vivenciado pelo Estado brasileiro que influencia diretamente os direitos específicos das pessoas idosas, já que muitos deles foram privatizados e direcionados por demandas mercadológicas. Isso se expressa pela transferência de responsabilidades com os idosos para as famílias, e incentivos a várias formas de previdência e medicina privadas, sendo essas substitutas do sistema de seguridade social. Esse ideário neoliberal é contextualizado pelo desmantelamento das políticas sociais no Brasil que são instrumentos de concretização de direitos de cidadania. Os direitos sociais têm sido contestados por esta perspectiva que preconiza o Estado mínimo e a transferência para a sociedade civil da responsabilidade com a produção de bens e serviços (PEREIRA, 2002).

Ainda durante a década de 1980, foram realizados seminários regionais para se discutir a questão do idoso no Brasil, com a participação de diversas entidades interessadas na criação de políticas sociais para idosos. Elaborou-se, então, o documento “Políticas para a Terceira Idade nos anos 90”, o qual foi encaminhado para o então presidente da república, Fernando Collor. Apesar da mobilização em torno do tema, a Política Nacional do Idoso (PNI), Lei 8842/994, só foi criada durante o governo Itamar Franco, em 1994. Marta Regina Pastor Bruno (2003) afirma que a PNI

\footnotetext{
reconhece o idoso como sujeito portador de direitos, define princípios e diretrizes que asseguram os direitos sociais e as condições para promover sua autonomia, integração e participação dentro da sociedade, na perspectiva da intersetorialidade e compromisso entre o poder político e a sociedade civil (BRUNO, 2003, p. 78).
}

Segundo Bruno (2003) a PNI foi pautada em dois eixos centrais: proteção social, que inclui questões como saúde, moradia, transporte, renda mínima; e inclusão social, que trata da inserção ou reinserção social de idosos em atividades educativas, socioculturais, organizativas, saúde preventiva, desportivas e ação comunitária. Tais direitos, por sua vez, são efetivados por meio de políticas sociais nas áreas de saúde, promoção e assistência social, educação, trabalho e previdência social, habitação e urbanismo, justiça e cultura, esporte e lazer. Pode-se afirmar que a PNI é um avanço na integração das políticas setoriais, propondo uma ação completa, que compreende o idoso como cidadão de direitos e protagonista de suas ações (COSTA; MENDONÇA; ABIGALIL, 2002). 
Em 1998, foi promulgada a Política Nacional de Saúde do Idoso (PNSI), proposta por profissionais de saúde, professores de universidades e técnicos do Ministério da Saúde. Essa política é vista como parte da PNI, com vistas ao envelhecimento saudável, buscando preservar a capacidade funcional, autonomia e qualidade de vida do idoso por meio da promoção do envelhecimento saudável, manutenção da capacidade funcional, reabilitação, capacitação de recursos humanos e apoio ao desenvolvimento de cuidados informais e apoio a estudos e pesquisas.

O Estatuto do Idoso (Lei 10.741/2003), sancionado em 2003 pelo Presidente Lula, atualmente regulamenta os direitos das pessoas com idade igual ou maior a 60 anos e dispõe sobre direitos fundamentais, determina obrigações às entidades assistenciais e estabelece penalidades para situações de desrespeito ao idoso. Afirma no artigo $2^{\circ}$ que

o idoso goza de todos os direitos fundamentais inerentes à pessoa humana, sem prejuízo da proteção integral de que trata esta Lei, assegurando-se-lhe, por lei ou por outros meios, todas as oportunidades e facilidades, para preservação de sua saúde física e mental e seu aperfeiçoamento moral, intelectual, espiritual e social, em condições de liberdade e dignidade (BRASIL, 2003, p. 9).

Nesse sentido são garantidos direito à vida, à saúde, à alimentação, à educação, à cultura, ao esporte, ao lazer, ao trabalho, à cidadania, à liberdade, à dignidade, ao respeito e à convivência familiar e comunitária, conforme o artigo $3^{\circ}$ da referida lei. Observa-se, portanto, que o Estatuto do Idoso é uma norma legal abrangente, resultado da junção de divesas postulações sobre os idosos, e que exige um redirecionamento das linhas de ação das políticas públicas.

É observado, então, que as políticas de atenção à população idosa já estão criadas, mas ainda não é possível visualizar a vida digna dos idosos brasileiros. Percebe-se que o Estado brasileiro, apesar de ter leis dirigidas às pessoas idosas, ainda não está preparado para enfrentar uma realidade de aumento da população idosa, o que implica uma reorganização dos serviços de saúde, previdenciários e de assistência social. 


\section{Capítulo 3}

\section{$\mathrm{O}$ idoso dependente e o cuidado na família}

Embora velhice não seja sinônimo de doença, é necessário considerar que os idosos têm maior comprometimento de sua saúde e probabilidade de apresentar determinadas doenças e incapacidades do que pessoas de outros grupos etários. Dados do IBGE mostram que, em 2003, 71,2\% dos homens e 83,4\% das mulheres acima dos 60 anos realizaram consulta médicas nos 12 meses anteriores à pesquisa, e que $9 \%$ dos homens e 8,4\% das mulheres foram internados no mínimo uma vez no mesmo período (CAMARANO, 2005). Nesse sentido, o objetivo desse capítulo é compreender a situação de dependência do idoso, especialmente em casos de demência, em relação ao contexto da família.

\subsection{Articulando fragilidade, autonomia e dependência}

De acordo com Davi Rumel et al (2004), o Brasil está em um processo de transição epidemiológica que deslocou o eixo de morbimortalidade de doenças infecciosas e problemas manterno-infantis para doenças crônico-degenerativas, resultantes do envelhecimento populacional, e causas externas, decorrentes principalmente de situações de violência.

Apesar das doenças crônico-degenerativas não estarem entre as principais causas de mortalidade entre idosos, implicam grandes conseqüências para a qualidade de vida tanto para os pacientes como para suas famílias, uma vez que levam a quadros mórbidos, perda da independência e/ou da autonomia (KARSCH, 2003a). Destaca-se que as principais causas de óbitos de idosos são: doenças do aparelho circulatório (44,6\%); sintomas, sinais e afecções mal definidas (22,5\%); neoplasias (11,5\%); e doenças do aparelho respiratório (7,1\%) (CAMARANO, 2005).

Pesquisas sobre idosos fragilizados ou dependentes por doenças crônicas e degenerativas são recentes no contexto brasileiro. Se de um lado há uma população idosa com plena capacidade funcional, autonomia e qualidade de vida, do outro, estudos epidemiológicos afirmam que a freqüência de idosos portadores de incapacidades varia entre $0,2 \%$ e $20 \%$ (KARSCH, 2003a).

Segundo Ana Amélia Camarano (2005), a dependência do idoso pode ser analisada a partir da falta de autonomia para lidar com atividades do cotidiano e da falta 
de renda. Neste sentido, observa-se que é baixa a proporção de idosos sem rendimento, representando aproximadamente 11\%, em 2003. Sobre a realização de atividades do cotidiano, dados do IBGE mostram que em 1998, 13,4\% dos homens e 17,1\% das mulheres com 60 anos ou mais não conseguiam ou apresentavam algum grau de dificuldade para alimentar-se, tomar banho ou ir ao banheiro sozinhos. Essas estatísticas foram reduzidas, em 2003, para 11,5\% dos homens e 15,0\% das mulheres. Já em relação a aqueles que não apresentam nenhuma dificuldade para realizar tais atividades, em 1998, era $86,6 \%$ entre os homens e $82,9 \%$ entre as mulheres, e em 2003 , $88,50 \%$ e 85\%, respectivamente (CAMARANO, 2005).

Debora Diniz (2006) afirma que a velhice torna o indivíduo mais vulnerável, o que não significa incapacidade para a vida social ou ausência de livre arbítrio. Essa vulnerabilidade identifica fragilidade, dependência e demanda por cuidado, e é resultado de um jogo de limitações individuais e estrutura social pouco sensível à demanda por cuidado. De acordo com o conceito de fragilidade proposto pelo Ministério da Saúde (BRASIL, 2006), trata-se de uma síndrome que envolve fatores biológicos, psicológicos e sociais que sugerem um estado mais vulnerável, ou seja, um risco maior de ocorrência de problemas clínicos como declínio funcional, quedas, hospitalização, institucionalização e morte.

A fragilidade é um fator determinante de incapacidade e dependência por implicar perdas na capacidade funcional ou limitações de diferentes origens, como doenças físicas e mentais e lesões. Entretanto, a dependência não é resultante somente da fragilidade, mas de um fenômeno multidimensional, no qual podem ser incluídos fatores mentais, físicos, econômicos, sociais e ambientais.

Essa condição chamada multidimensionaldidade pode ser física, psicológica e social e também pode ser analisada em diferentes níveis, como o comportamento, o pessoal, o situacional ou o interpessoal (TORRES; SÉ; QUEROZ, 2006). A dependência pode ser justificada por doenças incapacitantes, estados afetivos e vivências negativas, escassez ou inadequação de ajuda física ou psicológica, desamparo, desmotivação, inatividade, deteriorização geral (GOMES; DIOGO, 2006).

Segundo Stella Torres, Elizandra Sé e Nelma Queroz (2006), o avanço da idade aumenta a chance de ocorrência de fragilidades, de forma particular pela ocorrência de doenças e síndromes típicas da velhice. Todavia, situações de dependência não são 
exclusivas do envelhecimento e da velhice, mas podem estar presentes em diferentes momentos, como nascimento, infância e períodos de doença. A dependência em idosos, porém, apresenta características específicas como mudanças no campo biológico e social e nas interações com o ambiente, e acarreta, em geral, restrições físicas como locomoção, e cognitivas como dificuldades para tomar decisões e perda da autonomia. Também deve ser considerado que diferentes doenças e graus de fragilidade causam diferentes graus de dependência.

Para Luiz Roberto Ramos (2002), um idoso com uma ou mais doenças crônicas que leva uma vida normal, com suas doenças controladas, e expressa satisfação na vida, pode ser considerado um idoso saudável se comparado a um idoso que possui seqüelas e incapacidades de uma doença. Assim, a autonomia e a capacidade funcional podem ser tomadas como referência para um paradigma de saúde do idoso. A questão da normalidade como referência para saúde é trabalhada por Debora Diniz (2007) que afirma que esse conceito é frágil e baseado em dados estatísticos e em julgamentos estéticos, a partir de um valor moral sobre os estilos de vida.

Naira Lemos e Sônia Medeiros (2002) observam que a autonomia é a principal meta do desenvolvimento, sendo rejeitada pela maioria das pessoas a idéia de depender de outros na vida adulta. Além disso, enquanto o conceito de independência está ligado a possibilidade de sobrevivência sem ajuda para atividades instrumentais da vida diária e de autocuidado, o de autonomia trata da "noção do exercício do autogoverno, associado aos seus correlatos: liberdade individual, privacidade, livre escolha, autoregulação e independência moral” (LEMOS; MEDEIROS, 2002, p. 893). Neste sentido, a autonomia e a independência tornam-se indicadores de saúde e possibilitam verificar a qualidade de vida dos idosos.

Autonomia também pode ser entendida como “capacidade de decisão e comando sobre suas ações, de estabelecer e seguir suas próprias regras” (GOMES; DIOGO, 2006, p. 117). É um conceito mais abrangente do que independência pois é possível um idoso manter sua autonomia mesmo sendo dependente, ou seja, a capacidade de autogestão pode ser exercida mesmo que a pessoa tenha alguma incapacidade física ou cognitiva para uma determinada ação. Anita Liberalesso Neri e Cinara Sommerhalder (2002) afirmam que a dependência funcional é aquela associada a déficits em capacidades 
funcionais, entretanto, essas dificuldades para realizar atividades instrumentais da vida diária não implicam impedimento para o funcionamento psicossocial. Isso significa que

\begin{abstract}
mesmo a incapacidade funcional devida ao agravamento das doenças crônicas não impede o idoso de funcionar intelectual e socialmente, de solicitar e de oferecer ajuda a outros idoso e aos mais novos. Dito em termos simples, é possível ser inválido sem ser dependente, e o inverso também é verdadeiro. Além disso, independência física e autonomia são condições relacionadas, mas uma não é pré-requisito para a outra (NERI; SOMMERHALDER, 2002, p. 20).
\end{abstract}

A relação entre dependência e autonomia é analisada por Diniz (2007) em casos de deficiência. Nesse contexto é possível alguém ter lesões sem limitações da capacidade, ter problemas de desempenho e limitações sem lesões aparentes, ou ter problemas de desempenho sem ter limitações de capacidade ou lesões. Ainda no contexto da deficiência, Diniz (2007) discute a premissa da independência como valor ético para a vida humana. Enquanto o modelo social de deficiência compreende a deficiência como resultado de uma forma de organização social, sendo que, retiradas as barreiras, seria possível haver independência dos deficientes, a corrente feminista afirma que muitos deficientes jamais vivenciarão a independência ou capacidade para o trabalho mesmo que as barreiras sejam eliminadas.

A definição de independência proposta acima está relacionada à idéia de perda da capacidade funcional que inclui "a perda das habilidades físicas e mentais necessárias para a realização das suas atividades básicas e instrumentais da vida diária” (BRASIL, 2002, p. 15). As Atividades de Vida Diária (AVD) compreendem aquelas relacionadas ao autocuidado e que, em caso de dependência, requerem a presença de um cuidador direto para realizá-las como alimentar-se, banhar-se, vestir-se, mobilizar-se e ir ao banheiro. Já as Atividades Instrumentais da Vida Diária (AIVD) são relacionadas à participação do idoso em seu meio social e indicam a independência do indivíduo dentro de sua comunidade como, por exemplo, utilizar meios de transporte, manipular medicamentos, realizar compras, realizar tarefas domésticas, preparar refeições e cuidar das próprias finanças (BRASIL, 2006). Para avaliar a capacidade funcional de idosos para AVD e AIVD, são utilizados testes específicos que vão além da capacidade funcional orgânica e que incluem testes cognitivos e informações sobre cuidado, visando estabelecer a melhor forma de assistência à saúde do idoso. 


\title{
3.2. Demências: problema de saúde do idoso
}

Entre as doenças cerebrovasculares encontradas em idosos, as demências são as mais freqüentes, sendo que a Doença de Alzheimer (DA) representa mais de 50\% dos casos de demência em pessoas idosas (HERRERA JUNIOR et al, 1998). Além desse tipo existem: demência vascular, demência mista (Alzheimer e vascular), demência frontotemporal, demência por corpos de Levy e demência na doença de Parkinson. (SANTOS; RIFIOTIS, 2006).

Dados epidemiológicos estimam que mais de 15 milhões de pessoas sejam afetadas pela DA em todo o mundo, e sua prevalência vem aumentando de forma significativa. Nos Estados Unidos, essa é a quarta maior causa de óbitos na faixa etária entre 75 e 84 anos de idade e a terceira maior causa de incapacidade (MACHADO, 2002). De acordo com a definição da Portaria 703 do Ministério da Saúde, trata-se de

\begin{abstract}
uma síndrome decorrente de doença ou disfunção cerebral, atualmente de natureza crônica e progressiva, na qual ocorre perturbação de múltiplas funções cognitivas, incluindo memória, atenção e aprendizado, pensamento, orientação, compreensão, cálculo, linguagem e julgamento e produz um declínio apreciável no funcionamento intelectual de seus portadores e interfere nas atividades do dia-a-dia, como a higiene pessoal, vestimenta, alimentação, atividades fisiológicas e de toalete (BRASIL, 2002, p. 96).
\end{abstract}

É importante compreender o referido conceito, uma vez que esse norteia a política de saúde pública voltada para o atendimento de idosos com esse diagnóstico. A demência é, portanto, uma síndrome crônica e progressiva composta por sintomas do cérebro, especialmente na memória e altera diversos aspectos da vida humana, no âmbito cogntivo, fisiológico, social e familiar. A memória é a capacidade para reter e fazer uso posterior de uma experiência, condição necessária para desenvolver uma vida independente e produtiva. Um problema da memória é considerado como sério, quando afeta as atividades do dia-a-dia, ou seja, quando a pessoa tem problemas para recordar como fazer coisas cotidianas (BRASIL, 2006).

Segundo Silvia Maria dos Santos e Theophilos Rifiotis (2006), a prevalência de demências na velhice extrapola o âmbito biológico porque tem diferentes representações e repercussões na economia, polítca, sociedade e cultura, e afeta de modo particular as famílias, porque essas assumem, em geral, os cuidados.

Assumir a função de cuidador de um idoso dementado não é um papel assumido por um curto período de tempo e com perspectivas de melhora, porque na maioria dos casos o portador irá viver 10 ou 20 anos em situação de crescente dependência, requerendo atenção contínua nas 24 horas do dia (SANTOS; RIFIOTIS, 2006, p. 143). 
De modo geral, o processo demencial pode ser dividido em três fases: 1 . fase inicial tem como características lapsos de memória, dificuldades para tomar decisões e fazer planos, perda progressiva da capacidade de atenção, aprendizagem e iniciativa. Essa fase pode passar despercebida pela família porque os esquecimentos podem ser disfarçados. É comum que a pessoa fique deprimida nesta fase e evite a interação social; 2. fase intermediária é marcada pelo aumento da dependência no sentido da necessidade de supervisão e ajuda para autocuidado. As capacidades de julgamento e discernimento são prejudicadas e freqüentemente a pessoa inventa palavras e histórias, e não reconhece pessoas. 3. na fase final é observada a dependência total da pessoa, o que implica a necessidade de cuidados integrais no leito (CALDAS, 2002).

Para Célia Pereira Caldas (2002), é fundamental a equipe de saúde e a família conhecerem a evolução progressiva da doença e atuarem de forma específica em cada momento de acordo com as necessidades. Neste sentido, enquanto na primeira fase da doença é importante que os profissionais de saúde envolvam a família na assistência à saúde, no cuidado e no entendimento do diagnóstico e da doença, na fase intermediária, as ações dos profissionais devem ser centradas na prevenção de acidentes, orientações sobre alimentação, medicação e higiene, assim como suporte para o sofrimento da família, resultante da indiferença afetiva apresentada pelo paciente. Na fase final, então, é enfatizado o suporte familiar e apoio à família para o momento da morte do idoso.

\subsection{Família como fonte de cuidados}

O documentário Clarita (2007), dirigido por Thereza Jassouron ${ }^{7}$, apresenta esse contexto do cuidado ao idoso com Doença de Alzheimer na família, de forma bastante concreta. A diretora do curta-metragem, filha e cuidadora de uma idosa com Doença de Alzheimer, narra a relação com sua mãe desde antes do diagnóstico até a fase grave da doença, as implicações para a família, a tarefa de cuidadora, e inclusive, a necessidade de cuidadoras contratadas. Podem ser observadas as demandas de cada fase e os sentimentos da cuidadora, que ora representam gratidão e sensibilidade, ora são perpassados por frustração e cansaço.

\footnotetext{
${ }^{7}$ O documentário Clarita foi apresentado em uma audiência pública organizada pela Comissão de Seguridade Social e Família da Câmara dos Deputados em 27/9/2007.
} 
Naira Lemos e Sônia Lima Medeiros (2002) observam a importância de redes de suporte social para o idoso e sua família, entendidas como conjuntos hierarquizados de pessoas que mantêm entre si relações de dar e receber. É possível classificar esses sistemas de suporte social como formais, que incluem serviços de atendimento em hospitais, atendimento domiciliar, abrigamento e programas formais de capacitação de pessoal voltados para o atendimento a população idosa; e informais, compostos por redes de relacionamento entre membros da família, amigos e vizinhos.

De acordo com Caldas (2002), os idosos com doenças consideradas incapacitantes, em especial com dependência em alto grau como as demências, têm os cuidados necessários prestados principalmente por um sistema de suporte informal, composto por cuidadoras que podem ser familiares, amigos, vizinhos e membros da comunidade, cujas atividades são, em geral, voluntárias. Nesse sistema de suporte informal, predomina o cuidado oriundo da família, centrado na figura do cuidador.

A organização do cuidado familiar do idoso tem influência da tradição histórica e de fatores culturais, sendo que as mudanças nos padrões tradicionais de família apresentam um reflexo no cuidado do idoso. A transformação de famílias extensas em famílias nucleares, a redução da quantidade de filhos e a maior participação da mulher no mercado de trabalho, diminuem a disponibilidade para o cuidado (CALDAS, 2002).

Karsch (2003b) também reflete sobre as mudanças nas estruturas familiares e afirma que o conceito de família como o conjunto de pessoas residentes sobre o mesmo teto e com laços de parentesco e afinidade já não corresponde à realidade devido a alterações decorrentes de separações; divórcios e novas uniões; instabilidade no mercado de trabalho e movimentos migratórios nacionais e internacionais; maior tempo de vida das gerações e aumento do contingente de viúvas; idosos exercendo chefias de famílias, e a participação crescente da mulher no mercado de trabalho.

A centralidade do cuidado prestado pela família pode ser percebida no próprio Estatuto do Idoso que, no artigo $3^{\circ}$, faz referência, como obrigação da família, juntamente com a comunidade, a sociedade e o poder público, assegurar ao idoso direito à vida, à saúde, à alimentação, à educação, à cultura, ao esporte, ao lazer, ao trabalho, à cidadania, à liberdade, à dignidade, ao respeito e à convivência familiar e comunitária (BRASIL, 2003). 
De acordo com Caldas (2002), embora a legislação e políticas públicas primem pela assistência ao idoso por sua família, não se pode garantir que a família prestará um cuidado humanizado e adequado às necessidades do idoso. Neste sentido, cabe ao Estado reconhecer a necessidade e implantar estruturas de apoio ao idoso e suas famílias, que incluam, desde o atendimento ambulatorial do idoso ao suporte de uma rede social e de saúde para a família.

O cuidador principal pode ser definido como "aquele que tem a total ou a maior responsabilidade pelos cuidados prestados ao idoso dependente no domicílio" (CALDAS, 2002, p. 51). Ele pode ser auxiliado por cuidadores secundários, familiares, voluntários ou profissionais que realizam atividades complementares de cuidado, colaborando com o cuidador principal. Também é possível classificar o cuidador como formal, para o profissional contratado, seja ele auxiliar de enfermagem, acompanhante ou empregada doméstica; e informal, para os cuidadores familiares, amigos e voluntários da comunidade. Esses conceitos são importantes para compreender a problemática do cuidado do idoso, especialmente para a análise da pesquisa de campo.

Outra classificação considera os cuidadores como primários, secundários e terciários. Os cuidadores primários são os principais responsáveis pelo idoso e pelo cuidado e realizam a maior parte das tarefas. Os secundários podem realizar as mesmas tarefas que o cuidador primário, mas não têm o mesmo nível de responsabilidade e decisão, e geralmente atuam de forma pontual em algumas tarefas de cuidado. Os cuidadores terciários, por sua vez, são coadjuvantes e não possuem responsabilidade pelo cuidado, substituindo o cuidador primário em ocasiões específicas e esporádicas e realizando tarefas especializadas (NERI; SOMMERHALDER, 2002).

Não é necessário que o cuidador seja membro da família ou viva com o idoso, mas geralmente a escolha dos cuidadores segue os seguintes critérios: 1. parentesco direto com o idoso, ou seja, esposa, filha; 2. gênero do cuidador, sendo na maioria das vezes mulheres; 3. a distância física entre idoso e cuidador; 4. proximidade afetiva (KARSCH, 2003a). Karla Giacomin, Elizabeth Uchoa e Maria Fernanda Lima-Costa (2005) observam que geralmente a figura do cuidador informal emerge de relações familiares fragilizadas pela presença da doença e reorganizadas para atender às necessidades do idoso. Também é comum os cuidadores não terem conhecimento sobre quais cuidados realizar e nem sobre como desempenhar esse papel. 
Nota-se, ainda, que embora o cuidado do idoso no Brasil ocorra principalmente no contexto da família, essa organização do cuidado não se aplica a todos os casos. Existem idosos que não têm família, outros cujas famílias são muito pobres para prover os cuidados necessários, e há situações em que o relacionamento entre a família e a pessoa idosa é tão conflituoso que impede a realização de cuidados de forma adequada. Assim, embora na prática os cuidados sejam realizados na família, essa não pode ser vista como única fonte de cuidados (CALDAS, 2002).

Além dessas situações, outras dificuldades são vivenciadas pelos cuidadores. É comum perceber a sobrecarga do cuidador principal mesmo no caso dos cuidados serem distribuídos entre diferentes membros da família. Essa sobrecarga pode ser entendida como resultado da soma das atribuições familiares e emprego, da inversão de papéis dos membros da família, de sentimentos como desespero, raiva e frustração, estresse, e do aumento das despesas financeiras. A aceitação e falta de conhecimento sobre a doença pela família também podes ser consideradas como dificuldade (CALDAS, 2002).

Anita Liberalesso Neri e Virgínia Ângela de Lucena e Carvalho (2002) afirmam que o impacto do exercício do cuidado sobre o bem-estar do cuidador familiar é apresentado na maioria das pesquisas realizadas sobre o tema. Esse impacto é refletido na prevalência de doenças psiquiátricas, uso de drogras psicotrípicas, doenças somáticas, isolamento social, estresse pessoal e familiar e sentimentos de ter que cumprir uma obrigação pesada e causadora de tensão.

De acordo com Úrsula Karsch (2003a) a sociedade brasileira percebe a problemática dos idosos dependentes como individual e familiar, ou seja, sem a necessidade de uma rede de serviços que pudesse dar suporte aos cuidadores e cuidadoras. Entretanto, eles necessitam de apoio, esclarecimentos, demonstrações de cuidados físicos e visitas de profissionais de saúde, além de amparo social. Assim,

\footnotetext{
os cuidados devenvolvidos dentro das casas, invisíveis aos olhos do público e ignorados pelas autoridades e pelas organizações que poderiam se responsabilizar por uma rede de atendimento, permanecem ocultos e, por causa disso, não são amparados por quaisquer apoios, serviços externos ou políticas e programas (KARSCH, 2003a, p. 106).
}

Destaca-se ainda que oferecer apoio ao cuidador não se resume a transmitir informações sobre a doença e orientações gerais ao cuidado, mas possibilitar que os familiares, ao vivenciarem a tarefa de cuidar, estejam preparados para tomar decisões e a lidar com o idoso em suas diversas necessidades (CALDAS, 2002). A ausência de 
uma rede de suporte de saúde e social para os cuidadores no Brasil também é percebida por Santos e Rifiotis (2006) que afirmam que a maneira como as famílias lidam e se organizam para assumir os cuidados é muito variada e envolve diferentes pessoas, além de implicar variadas negociações, aproximações, dilemas e conflitos. Já para Karsch (2003b) o cuidador familiar precisa receber orientações sobre como proceder nas situações mais difícies e receber, em casa, visitas de profissionais para supervisão e capacitação.

Irani Argimon e Clarissa Trentini (2006) afirmam que o cuidar do idoso, em especial em casos de demência, é freqüentemente percebido como um fardo pesado. É comum os familiares responsáveis pelo cuidado não entenderem as características da doença e sua progressiva evolução, sendo as informações restritas aos cuidados básicos de alimentação, higiene e medicação. Também são percebidas reestruturação e modificação dos papéis do grupo familiar a partir da organização de horários, atividades e cuidados.

Outra discussão pertinente sobre o cuidado do idoso dependente trata da institucionalização. A internação em instituições como asilos e manicômios é a modalidade mais antiga de atenção ao idoso e outros grupos sociais considerados indignos de conviver em sociedade, como pobres e loucos. Somente a partir da década de 1960 a família e a comunidade passaram a ser valorizados como espaços de atendimento a essas necessidades (LEMOS; MEDEIROS, 2002).

Segundo Caldas (2002) a maior causa de asilamento e outras formas de institucionalização para idosos é a falta de suporte familiar. Assim, não há justificativa para defender a institucionalização de idosos que vivenciam um processo demencial, já que não há garantias de que no âmbito institucional serão atendidas suas necessidades. Giacomin (2005), por sua vez, observa que não existem estruturas intermediárias de cuidado entre a família e a instituição de longa permanência para idosos, como centrosdia e hospitais-dia, o que possibilitaria uma maior assistência às famílias.

Destaca-se ainda que o papel do cuidador não se encerra com a institucionalização, ocorrendo apenas uma mudança de foco. De acordo com pesquisas, é observada uma maior tendência de filhas institucionalizarem seus pais, do que esposas, principalmente quando vivenciam altos níveis de estresse e sobrecarga (NERI; 
SOMMERHALDER, 2002). Neste sentido, Karsch (2003b) apresenta a seguinte reflexão:

$$
\begin{aligned}
& \text { cuidar do idoso em casa é, com certeza, uma situação que deve ser } \\
& \text { preservada e estimulada, todavia, cuidar de um indivíduo idoso e } \\
& \text { incapacitado durante } 24 \text { horas sem pausa não é tarefa para uma mulher } \\
& \text { sozinha, geralmente com mais de } 50 \text { anos, sem apoios nem serviços que } \\
& \text { possam atender às suas necessidades, e sem uma política de proteção para o } \\
& \text { desempenho deste papel (KARSCH, 2003a, p. 863). }
\end{aligned}
$$

Além do debate sobre a institucionalização do idoso dependente, é importante refletir sobre o papel e a formação do cuidador contratado, percebido, em muitos casos, como uma alternativa à sobrecarga dos cuidadores principais. Observa-se a escassez de estudos sobre o perfil de cuidadores contratados, que incluem desde empregadas domésticas até profissionais como técnicos de enfermagem.

A emergência do cuidador formal como uma nova categoria profissional é, de acordo com Virgínia Lúcia Reis Maffiotelli, Cristina Loyola e Fórtunée Nigri (2006), resultado do contexto social que exige que os membros da família estejam inseridos no mercado de trabalho, a demanda e oferta que se inscrevem na fragmentação de saberes, prestação de serviços desregulamentada, carência de uma rede de serviços especializados e exigência de minimizar os custos. É importante para esses cuidadores, então, levarem em conta a especificidade da velhice e as constituições orgânicas da velhice, juntamente com suas patologias.

A partir da reflexão nota-se a complexidade dessa realidade, que envolve o cuidado prestado pelas famílias aos idosos dependentes, centralizado na figura das cuidadoras. Embora a literatura apresente a família como uma rede de suporte e cuidado ao idoso, essas atividades são realizadas primordialmente por mulheres próximas ao idoso, como esposas e filhas. Essa sobreposição da mulher ao conceito de familia enfatiza a idéia de que o cuidado é um atributo feminino, o que acarreta implicações para as políticas públicas de atenção à saúde do idoso e cuidadoras. Destaca-se ainda a situação de vulnerabilidade das cuidadoras apontada na literatura, relacionada à fragilidade física, psicológica, emocional e social, refletida nos dados do estudo de caso da presente pesquisa, que serão apresentados no próximo capítulo. 


\section{Capítulo 4 \\ Pesquisa de campo}

Diversos estudos têm sido realizados com cuidadores e cuidadoras para identificar o perfil das pessoas que realizam o cuidado e compreender quais os significados desta tarefa e as dificuldades vivenciadas. A literatura aponta que, na maioria dos casos, as mulheres desempenham a tarefa do cuidar, salvo por razões específicas. No contexto brasileiro a mulher é tradicionalmente a cuidadora (KARSCH, 2003b; GIACOMUN, 2005; MAFFIOLETTI; LOYOLA; NIGRI, 2006; NERI; SOMMERHALDER, 2002; ATTIAS-DONFUT, 2004).

Essa realidade foi percebida na pesquisa de campo por meio das entrevistas com cuidadoras atendidas no Centro de Medicina do Idoso (CMI). O presente capítulo está dividido a partir dos assuntos abordados com as cuidadoras de modo a possibilitar maior aprofundamento das narrativas e debate teórico. É dado destaque ao sigilo e anonimato das entrevistadas na apresentação das narrativas, sendo informada apenas a idade e relação de parentesco com o idoso, dados considerados importantes para a pesquisa.

\subsection{Início do tratamento e compreensão sobre a Doença de Alzheimer}

Inicialmente é dado destaque à diversidade de motivos que fizeram as cuidadoras procurarem atendimento médico ao idoso. As entrevistadas citam desde mudanças no comportamento e o aumento da ocorrência de esquecimentos, até o acontecimento de um fato marcante, como esquecer uma panela no fogão ligado ou não lembrar o caminho de volta para casa, conforme as seguintes falas:

\footnotetext{
Uma vez ela deixou uma panela no fogo, deixou lá e esqueceu. Ela sentou no sofá e esqueceu mesmo. Ela dormiu e só acordou com a casa cheia de fumaça. A panela ficou preta. Às vezes ela pergunta muito "Que dia é hoje?”. Ela fala três, quatro vezes. É como se desse uma branco (Entrevistada 3, 44 anos, filha).
}

No começo, quando ela começou a esquecer as coisas, a gente achava que era normal, que toda pessoa mais velha esquece as coisas, mas um dia ela se perdeu. Saiu de casa e ninguém sabia onde tava. Daí a gente chamou os vizinhos e encontrou ela lá longe, perto do mercado, sozinha. Ela não sabia como voltar para casa. Não sabia nem o nome dela. Foi por isso que a gente procurou o médico. (Entrevistada 8, 38 anos, filha).

Em ambos os relatos percebe-se a falta de conhecimento sobre a doença e seus sintomas, além da idéia de que esquecer, no período da velhice, é algum esperado ou 
normal. Isso implica um diagnóstico tardio e uma maior progressão da doença antes de sua descoberta e do início do tratamento. Estudo realizado por Deusivânia Vieira da Silva Falcão (2006) no CMI com filhas cuidadoras e suas relações familiares, também constatou a ida tardia a consultórios especializados por desconhecimento dos principais sintomas da doença ou por achar comum perder a memória no processo de envelhecimento.

De acordo com Célia Pereira Caldas (2002), a fase inicial do processo demencial passa despercebido em vários casos porque as pessoas conseguem disfarçar ou compensar os lapsos de memória. O déficit de memória só começa a ser percebido efetivamente na progressão da doença, quando se junta a dificuldades de fala e compreensão, perda da capacidade de atenção, iniciativa e interação social. A narrativa da Entrevistada 7 chama atenção porque a família desconfiou do diagnóstico da doença após a divulgação de uma reportagem sobre Doença de Alzheimer na mídia:

\footnotetext{
Apareceu sobre essa doença na TV. Não lembro se foi Fantástico ou Globo Repórter. Mas eu vi o caso que apareceu e o que a pessoa fazia, de esquecer onde estava, não saber que dia era, se perder na rua, e tudo isso já tava acontecendo com o meu pai. Foi por isso que a gente foi procurar o médico. Se não tivesse visto na TV, nem sabia que Alzheimer existia (Entrevistada 7, 42 anos, filha).
}

Sobre o início do tratamento no CMI, a maioria das entrevistadas afirmou ter sido encaminhada por profissionais do setor público ou privado, de áreas como Medicina e Psicologia. Algumas cuidadoras também contaram conhecer o serviço oferecido no CMI por meio de vizinhos e amigos. Também foi citada a escolha do serviço para o tratamento por se tratar de um serviço de referência ao atendimento a idosos com Doença de Alzheimer.

A Entrevistada 6 destaca o desconhecimento de alguns profissionais de saúde sobre a doença. Ela narrou a experiência de sua sogra, que passou um ano sendo atendida em um serviço particular com o tratamento inadequado para a doença.

\footnotetext{
Passei por outros médicos que não conheciam bem a doença, receitaram medicamentos que não eram para Alzheimer e quando eu cheguei aqui vi que aqui têm pessoas que entendem mesmo e sabem o que fazer. (...) Eu ouvi falar que aqui tinha um atendimento para o idoso, e que era muito bom. Consegui o telefone, liguei e coloquei o nome dela na lista. Depois de uns oito meses chamaram e eu vim com ela pra consulta. Foi chocante ver que tudo que ela tava tomando de remédio foi cortado porque não servia para o que ela tinha (Entrevistada 6, 39 anos, nora).
} 
Na pesquisa realizada por Falcão (2006), foram encontradas cinco concepções gerais de cuidadoras sobre a Doença de Alzheimer: doença que provoca a perda da memória; doença que é desencadeada por fatores diversos como hereditariedade, personalidade, aspectos espirituais, problemas pessoais ou eventos ocorridos na vida do familiar; doença degenerativa do cérebro; doença que deixa a pessoa desorientada; e doença que não possui cura. Nas entrevistas realizadas, a forma mais recorrente de compreensão da doença foi como doença de cabeça que não apresenta sintomas físicos.

A gente procurou ajuda porque ele foi no médico e apresentou um problema na cabeça. Isso já faz uns sete anos. (...) Ele só tem Mal de Alzheimer. O resto está tudo bom” (Entrevistada 4, 74 anos, esposa).

Ela não tem nada de doença do corpo. Nada de pressão alta, de derrame, de infarto. Não tem nada disso. No último exame de sangue deu tudo bem. O problema dela só é na cabeça mesmo. Se você olhar ela, vai dizer que ela é bem saudável, mas se ela abrir a boca, não vai falar nada com nada (Entrevistada 8, 38 anos, filha).

Foi observado que essa falta de sintomas fisiológicos da doença dificulta a compreensão das cuidadoras sobre a própria doença e sua progressiva evolução e faz as cuidadoras explicarem-na, principalmente, a partir do déficit de memória e das mudanças no comportamento. Percebeu-se que a maioria das cuidadoras entende que a doença não tem cura, entretanto, muitas afirmaram ter esperança e acreditarem que alguma descoberta científica será feita neste sentido.

Aprendi muito desde que ele começou o atendimento aqui. Já sei que não tem cura, que só vai piorando, mas que se a gente cuidar direito, demora mais pra ele piorar. A gente não pode deixar ele um minuto sozinho se não ele apronta. Guarda sapato na geladeira, esconde comida embaixo da cama. Tem que ficar sempre de olho (Entrevistada 7, 42 anos, filha).

O que eu vejo é que a memória vai piorando. Ela não consegue mais lembrar nem do nome dos filhos e dos netos, e daí pergunta pra gente "Quem é você?” Eu também vejo que ele mudou muito o jeito de ser. Agora ele faz coisas que não fazia antes e deixou de fazer coisas que ele gostava muito. (Entrevistada 18, 32 anos, neta).

Eu sei que é difícil, mas se Deus quiser, ela vai melhorar. (...) Cada vez que ela lembra o nome dos filhos, dos netos, acende uma esperança (Entrevistada 10, 35 anos, neta).

Neste sentido, comprova-se a afirmação de Silvia Santos e Theophilos Rifiotis (2006), segundo a qual é comum os familiares de idosos com demência considerarem as informações dadas a respeito da doença insatisfatórias, especialmente em relação à inexistência de um tratamento efetivo e da impossibilidade de cura. Isso gera uma recusa por parte dos familiares em aceitar o diagnóstico e seu caráter progressivo e 
degenerativo. Outra dificuldade de aceitação da doença é decorrente das mudanças de comportamento do familiar mencionadas pelas cuidadoras, como fazer birra, brigar, xingar, gritar, ser agressivo, desobediente, teimoso, apatia.

Às vezes eu não sei se é Alzheimer mesmo e acho que só é birra dela. Ela xinga, reclama, responde, fala palavrão, coisa que nunca tinha feito antes. Eu sei que o médico disse que é isso, mas não sei se realmente é. Parece que ela faz só pra irritar, só pra incomodar mesmo (Entrevistada 16, 55 anos, filha).

A gente se dava bem antes. Ele é meu pai e não posso tratar ele mal. Desde que minha mãe morreu eu cuido dele porque só tenho irmãos e eles não cuidam bem dele. Na verdade, nem sabem cuidar. Agora tá mais difícil porque quando eu falo para ele não fazer uma coisa ele briga, xinga. Ontem mesmo eu falei que não era para ele sair de casa, mas ele me xingou tanto. Eu até entendo que é por causa da doença que isso aocntece, mas não é bom ver ele assim (Entrevistada 20, 68 anos, filha).

Percebeu-se que o conhecimento das cuidadoras sobre o caráter progressivo da doença ocorre à medida que elas convivem diariamente com as alterações decorrentes desse processo. A Entrevistada 9, cujo esposo apresenta o diagnóstico da Doença de Alzheimer há aproximadamente oito anos, relatou:

Quando a gente descobriu a doença eu não entendia nada. Como é que ele podia estar doente se não sentia dor, se não mudou nada no corpo? E quando o médico disse que era Alzheimer eu fiquei mais confusa porque ninguém conhecia isso. Era normal achar que todo velho ficava caduco. Agora tá mudando. Aparecem mais coisas na televisão sobre os idosos, sobre os velhos, mas naquela época não. Então quando o médico disse que era Alzheimer e não tinha cura e que ia chegar uma hora que ele ia parar de caminhar, de falar, de fazer tudo, eu fiquei chocada. Não acreditei. Mas essa fase está chegando e ele não tá mais falando, anda de cadeira de roda, usa fralda. Qual será a próxima fase? (Entrevistada 9, 68 anos, esposa).

Outro elemento da doença, citado pelas entrevistadas, trata da inevitável morte do idoso. Nota-se que as cuidadoras que relataram a proximidade da morte realizam o cuidado de idosos em fase grave, quando utilizam fraldas e cadeiras de roda. Para elas, é observada a necessidade de apoio social e psicológico por sentirem grande sofrimento em relação à perda.

A gente se sente triste, mas o que a gente pode fazer? Pede ajuda para Deus para eu ter força para dar assistência a ela. Às vezes eu me levanto várias vezes de noite e eu olho para ele e parece que ele está morto. Já não parece mais a mesma pessoa. (...) Dentro de mim existe solidão. Por mais que ele ainda exista, a gente não se comunica mais (Entrevistada 1, 81 anos, esposa).

Primeiro eu tinha medo da morte dela, mas a gente acaba vendo o tamanho das dificuldades. Ela vai cumprir o tempo que Deus quer e a gente vai ter que aceitar isso. Não vai ser fácil, mas faz parte da vida (Entrevistada 2, 57 anos, filha). 
Percebe-se, portanto, que as cuidadoras, de modo geral, compreendem de forma adequada a Doença de Alzheimer e sua progressiva evolução, embora tenham dificuldade de esperar o que virá em uma próxima fase da doença. Também foi observada a confiança e respeito das cuidadoras ao serviço oferecido no CMI, sendo esse considerado um serviço de qualidade, com profissionais comprometidos e que orientam as cuidadoras sobre como desempenhar as tarefas do cotidiano. As entrevistadas ainda relataram que cada fase da doença exige cuidados específicos e formas diferenciadas de apoio e atendimento.

\subsection{Relacionamento entre cuidadora e idoso: Por que cuidar?}

As entrevistas também abordaram como era o relacionamento da cuidadora com o familiar com Doença de Alzheimer antes do diagnóstico da doença e depois, com vistas a observar as mudanças ocorridas. De acordo com Teresinha Mello da Silveira, Célia Caldas e Terezinha Carneiro (2006) compreender a história do relacionamento entre cuidadora e familiar é importante para a construção da subjetividade da cuidadora já que essa baseia-se no relacionamento com a pessoa cuidada.

Pode-se categorizar as respostas das cuidadoras sobre o relacionamento com o paciente antes da doença em três blocos gerais: 1. cuidadoras afirmaram ter um bom relacionamento com o idoso antes do diagnóstico da doença; 2. cuidadoras afirmaram que o relacionamento era permeado por conflitos; 3 . cuidadoras que não tinham proximidade com o idoso por morarem em diferentes residências, inclusive em cidades diferentes. O relato abaixo enfatiza a experiência de não morar com o idoso antes da doença.

\footnotetext{
Ela passou a morar comigo depois que já tinha Alzheimer. No início a gente deixou ela morando sozinha, depois foi vendo que precisava ficar com mais alguém. Daí tentamos colocar uma cuidadora pra morar com ela, mas não deu certo. A titia sempre brigava com ela, reclamava que ela tava roubando comida, e por isso resolvemos levar ela pra morar lá em casa com a gente (Entrevistada 12, 54 anos, sobrinha).
}

Nas entrevistas observou-se que diversos foram os motivos que fizeram as cuidadoras tomarem essa responsabilidade do cuidado: ser mulher; ser esposa; morar próximo ao familiar; não ter outros familiares; ter recebido a responsabilidade do 
próprio familiar antes do início da doença; não possuir marido ou filhos; sentimento de gratidão ou responsabilidade.

Lá em casa, quando meu pai ainda tava vivo, eu cuidava dos dois porque eu não tenho marido, filhos, e como morava com eles, era mais fácil porque meus irmãos têm a família deles já, e daí fica difícil pra eles virem aqui cuidar (Entrevistada 14, 69 anos, filha).

Minha mãe sempre cuidou de mim, me guardou nove meses na barriga, me ensinou tudo que eu sei. Eu tinha que pagar pra ela tudo isso de alguma forma, e agora que ela tá doente e precisa de mim, eu dou o que eu posso para ela (Entrevistada 16, 55 anos, filha).

A princípio quando a gente casa, a gente assume um compromisso muito grande, na saúde e na doença. Eu tenho fé em Deus de que vai até o fim. Eu nem posso abandonar ele agora, nessa situação (Entrevistada 19, 72 anos, esposa).

É visível a emergência de uma discussão sobre gênero e cuidado. Segundo Anita Liberalesso Neri e Cinara Sommerhalder (2002) na maioria dos países ocidentais a tarefa de cuidar em família é uma atribuição da mulher, seja o cuidado realizado aos filhos, à casa, ao cônjuge, aos doentes ou aos idosos. Essa atribuição de papéis segue normas culturais que dão ao homem a tarefa do sustento da sobrevivência material da família e a autoridade moral, e para a mulher a função de organização da vida familiar.

Considerando que as mulheres têm uma expectativa de vida maior que a dos homens, e, em geral, são mais novas que os maridos, a cuidadora familiar preferencialmente é a esposa. No caso da ausência da esposa, são escolhidos descendentes de segunda geração, sendo a filha mais velha a candidata mais provável. Essa seleção da cuidadora também é influenciada pelo estado civil das possíveis cuidadoras, e se elas têm ou não filhos. Raramente o cuidador é outro parente ou uma pessoa jovem, e mais raramente ainda é homem.

De acordo com Claudine Attias-Donfut (2004), o surgimento de uma sociedade multigeracional, na qual uma geração cuida ao mesmo tempo de seus idosos, filhos e netos, demandou novas relações quanto ao cuidado. Essa rede entre gerações, compõe um ciclo de reciprocidade direta, por parte dos filhos, pela ajuda que eles receberam, e indireta, pelas ajudas que deram aos próprios pais. Os homens, porém, intervêm duas vezes menos do que as mulheres em tarefas relativas ao cuidar e geralmente realizam atividades menos focalizadas nas atividades domésticas e cuidados pessoais. 
A mulher assume o cuidado mesmo quando trabalha fora de casa, sendo as conseqüências para as cuidadoras ainda mais intensas, como redução de atividades de lazer e vida social. Há, portanto, uma expectativa social de que as mulheres assumam o cuidado. Porém, o aumento da população idosa e a inserção da mulher no mercado de trabalho está exigindo uma reestruturação desses papéis construídos socialmente, uma vez que as cuidadoras estão cada vez menos disponíveis para atender os idosos dependentes (NERI; SOMMERHALDER, 2002).

Debora Diniz (2007) trata da questão do cuidado a partir da perspectiva de Eva Kittay e afirma que o cuidado e a interdependência são princípios que estruturam a vida social. Ao contrário da idéia da independência como valor central, considera-se que a dependência é inevitável ao longo da vida, e, mais do que isso, que há pessoas que necessitam de cuidado como condição de sobrevivência.

Compreendendo que o impacto da Doença de Alzheimer vai além da saúde do idoso e atinge também sua família, João Carlos Barbosa Machado (2002) propõe que essa deva ser considerada uma doença familiar e social uma vez que gera desagregação e desestruturação nas relações pessoais, financeiras e emocionais. A descoberta da doença alterou a dinâmica familiar no relato de todas as entrevistadas, sendo que essas mudanças incluem o aumento de gastos e dificuldades financeiras, cansaço e sobrecarga, dificuldades emocionais, conflitos familiares, dificuldades em realizar o cuidado, falta de apoio de outros familiares.

Santos e Rifiotis (2006) afirmam que várias situações de conflito ocorrem entre o cuidador principal e os outros membros da família, como a responsabilidade e desgaste físico e emocional do cuidador, a adaptação de projetos individuais à condição de cuidado, reclamações e cobranças dos outros membros da família A Entrevistada 13 contou a dificuldade de seu marido compreender o estado de saúde de sua mãe:

\footnotetext{
É difícil ter que cuidar de minha mãe sozinha, e ainda ter marido e filhos pra cuidar. Não é fácil. Meu marido, quando eu peço, ajuda, mas não aceita muito ela ter que morar aqui. Nenhum irmão meu mora aqui em Brasília, e se ela não ficar lá em casa, vai pra onde? Não posso colocar minha mãe num asilo (Entrevistada 13, 49 anos, filha).
}

Apesar de a maioria das cuidadoras afirmar ter apoio de outros membros da família para a realização do cuidado, a sobrecarga resultante da centralização do cuidado e ausência de outras pessoas para colaborarem efetivamente foi vista em diversas narrativas. 
Meus irmãos vão lá de vez em quando, mas eu também nem cobro. Eu sei que eles trabalham muito, têm filhos pra cuidar, mulher, e tudo. Eu não tenho filhos e daí fica mais fácil. Quando eu tenho que sair, eu chamo a vizinha pra ficar com ele, e ela aceita, cuida direitinho. Não posso deixar ele em casa sozinho. Mas é difícil porque às vezes eu tenho que sair e não tem quem ficar com ele (Entrevistada 7, 42 anos, filha)

Quem olha o remédio sou eu, mas eu preciso da menina [cuidadora contratada] para ficar com ela durante o dia. Eu trabalho e ela não pode ficar sozinha nem um minuto, sempre tem que ficar alguém de olho. E eu também tenho três filhos pequenos. Às vezes parece que tenho quatro crianças em casa (Entrevistada 15, 46 anos, nora).

A gente fica muito presa cuidando dele, não pode sair. Eu acho que estou cansada, precisando viajar. Mas se eu sair, não sei quem vai ficar cuidando dele, se vai cuidar direito, se vai saber dar os remédios (Entrevistada 11, 72 anos, esposa).

Encontram-se, em oposição a essas dificuldades, pontos positivos do cuidado. A tarefa de cuidadora foi citada por algumas entrevistadas como missão divina; resultante da reciprocidade pelos anos em que o familiar com Doença de Alzheimer já havia cuidado da família; e a responsabilidade e aprendizagem no cuidado, conforme os seguintes relatos:

Eu sinto que estou a serviço de Deus. Se isso está acontecendo é vontade de Deus. Ele não ia me dar uma tarefa que eu não conseguisse fazer (Entrevistada 2, 57 anos, filha).

Os pontos positivos do cuidado são exercitar a tolerância, a paciência, a compaixão. Você tem que aprender a lidar com as diferenças. Meus filhos estão aprendendo que a vó deles é doente. Foi difícil a mais nova de seis anos entender porque as duas disputam atenção (Entrevistada 6, 39 anos, nora).

\subsection{Rotina e os significados do cuidar}

As narrativas das cuidadoras a respeito de suas rotinas foram marcadas por atividades profissionais e atividades de cuidado com o idoso. Algumas entrevistadas relataram realizar atividades pessoais que visam ao seu bem-estar como participar de atividades religiosas, fazer trabalhos manuais, leituras e passeios. Observa-se que todas as entrevistadas que trabalham fora do lar centralizam sua rotina nas atividades profissionais e necessitam da ajuda de outros familiares ou de uma cuidadora contratada para realizar as atividades de cuidado. Já aquelas cuidadoras que não estão trabalhando, seja por estarem aposentadas ou desempregadas, disponibilizam mais tempo para o cuidado do familiar. A Entrevistada 3, por exemplo, disse que as atividades de cuidado são mais intensas no momento em que ela está desempregada: 
Eu estou desempregada e tudo que eu estou fazendo é para ela. Tenho que aproveitar porque eu sei que quando começar a trabalhar não vou ter tanto tempo livre (Entrevistada 3, 44 anos, filha).

A junção de atividades domésticas e de atividades de cuidado é relatada por várias cuidadoras, especialmente as mais idosas. Karla Giacomin, Elizabeth Uchoa e Maria Fernanda Lima-Costa (2005) afirmam que as esposas que realizam cuidados a seus esposos dependentes, em geral não consideram essa acumulação de tarefas como um fardo, mas como uma atribuição própria do casamento. O cuidado com a casa, roupa e alimentação faz parte do papel de esposa, sendo o compromisso de cuidar do marido também assumido no casamento. Entretanto, apesar de as cuidadoras não considerarem o peso dessa tarefa, destaca-se que tratam-se de pessoas idosas e que tendem a apresentar problemas de saúde.

Agora estou mais em volta dele, cuidando mesmo. Limpo a casa, faço comida para ele, ajudo no banho porque se deixar, ele não toma banho não, diz que está sempre limpo. Lavo roupa, mas sempre ligada no que ele tá fazendo. Ele gosta muito de ver televisão. Daí eu deixo ele sentado vendo a Sessão da Tarde enquanto arrumo as coisas e ele gosta. Não sei se ele entende direito, mas ri muito (Entrevistada 9, 68 anos, esposa).

Os significados do ato de cuidar, citados pelas cuidadoras, foram muito expressivos e relacionados tanto com a compreensão sobre a doença como com a rotina de cuidado. Percebe-se que a maioria das compreensões sobre o cuidado incluiu atividades instrumentais, relacionadas à doença e a necessidades humanas básicas, como alimentar-se, tomar banho, dormir, e fatores afetivos e emocionais. Embora a maioria das cuidadoras tenha enfatizado a responsabilidade do cuidado ao idoso por meio do controle da medicação, ida a consultas médicas, realização de exames, e cuidado com alimentação e higiene pessoal, várias delas, além desses aspectos, consideraram a importância do carinho, afeto e amor no cuidado, conforme os relatos a seguir:

Cuidar é um conjunto de coisas. Quando tem o nome de cuidado, é no geral carinho, estar presente, conversar, ajudar a tomar remédio... Não basta se preocupara com a doença, mas dar bem-estar para a pessoa (Entrevistada 3, 44 anos, filha).

Para mim, cuidar é antes de tudo, responsabilidade. A pessoa quando pega alguém para cuidar tem que ter muita responsabilidade. Mesmo quando não é da família, como esses cuidadores que a gente paga. Tem que ter dedicação e responsabilidade. Eu fico preocupada com o futuro porque eu não sei o quanto de cuidado ela vai exigir daqui a um ano, dois anos (Entrevistada 5, 47 anos, filha).

Cuidar é além de você ter que estar atento ao físico, é você ver que ele não dá conta de nada. Tem que dar comida, ajudar no banho, dar atenção. Ele tem que ter cuidado sempre (Entrevistada 17, 77 anos, esposa). 
Cuidar é ficar de olho, é dar carinho, dar o que ela precisa. Eu cuido dela sempre. Desde a hora que eu acordo, porque ela dorme no meu quarto, e faço café, almoço, lavo roupa, limpo a casa, tudo pra ela. Faço tudo. Levo pra consulta, pra exame. Quando ela pede pra ir pra igreja, eu vou com ela. Isso é cuidar. Ficar sempre junto. (Entrevistada 8, 38 anos, filha)

Quanto às orientações e dificuldades sobre o cuidado, a maioria das cuidadoras relatou ter obtido informações sobre o cuidado com os profissionais do CMI. Além disso, foi mencionado o Grupo Conviver como fonte de orientação e a busca de informações na internet. ${ }^{8}$ Em geral, essas informações são compartilhadas com outros membros da família o que possibilita a formação de uma rede de suporte familiar mais efetiva.

Já assisti algumas reuniões aqui com o Grupo Conviver. Então, tô mais ou menos por dentro. Lá em casa todo mundo tem informação. Já li muito sobre essa doença, mas minha filha sabe muito mais. Lá em casa todo mundo lê para saber e acompanhar o tratamento (Entrevistada 4, 74 anos, esposa).

Eu só fui entender melhor a doença aqui quando me passaram o livro com as orientações. Lá em casa só eu li, mas passei as informações para todo mundo (Entrevistada 6, 39 anos, nora).

Cuido dele do jeito que me ensinaram aqui. Sei a hora de dar os remédios, como dar os remédios, isso eu aprendi. Também tirei uns tapetes que tinham no chão porque se não ele podia cair, escondi as facas que cortam mais, e sempre tiro a chave da porta porque se não ele sai de casa. Não é fácil cuidar, mas a gente se vira, vai aprendendo ( Entrevistada 7, 42 anos, filha).

A partir dos relatos das entrevistas, é possível perceber a complexidade da Doença de Alzheimer e as diversas implicações para a família e cuidadoras. Percebe-se que a compreensão das cuidadoras sobre o cuidado perpassa tanto a compreensão da doença como a relação com o idoso cuidado e relações e conflitos com outros membros da família. Além disso, merece destaque a inclusão de fatores afetivos e emocionais no ato de cuidar o que amplia uma visão instrumental do cuidado, restrito a medicamentos, exames e consultas médicas.

\footnotetext{
${ }^{8}$ O Grupo Conviver tinha como principal objetivo informar o público em geral sobre os sintomas, cuidados, tratamentos e outros assuntos relacionados às síndromes demenciais, especialmente da Doença de Alzheimer. Para tanto, realizava encontros mensais com técnicos, especialistas e profissionais de saúde no auditório do Hospital Universitário, além da distribuição de materiais informativos. Devido a dificuldades financeiras e fatores burocráticos o grupo parou de realizar suas atividades em 2007.
} 


\section{Considerações finais}

O envelhecimento populacional impõe novas demandas sociais e de políticas públicas. Na sociedade brasileira a relação entre entre velhice e doença ainda está muito presente. Entretanto, apesar desse grupo etário apresentar maior vulnerabilidade para desenvolver determinadas doenças, não é correto afirmar que todo idoso será doente.

Nesse contexto de doenças crônico-degenerativas próprias da velhice, as demências, em especial a Doença de Alzheimer, merecem destaque devido ao aumento de sua ocorrência e às implicações para o idoso e sua família. Percebe-se que, embora a literatura afirme que o cuidado seja prestado pela família, a tarefa de cuidar é centralizada na figura de uma cuidadora, que pode contar ou não com a colaboração de outros cuidadores ou cuidadoras. Destaca-se que a idéia de que o cuidar é uma atribuição feminina e que cabe as mulheres esteve presente na narrativas das várias cuidadoras.

O impacto do diagnóstico da Doença de Alzheimer também foi observado nas entrevistas com as cuidadoras que expressaram desconhecimento sobre os sintomas da doença e dificuldades sobre como cuidar do idoso dependente. As evidências da pesquisa ainda apontaram que as cuidadoras compreendem que as necessidades do idoso com Doença de Alzheimer são amplas e variadas e não se restringem à doença. Nesse sentido, os cuidados são prestados por meio de tarefas instrumentais, como alimentação, dar banho, controlar medicação e realizar consultas, com a junção de fatores subjetivos, afetivos e emocionais, que complexificam a relação entre cuidadora e idoso.

Também devem ser consideradas as especificidades da doença, de modo particular, sua progressiva evolução. A construção de uma rede de apoio e orientação própria para cada etapa da doença é um fator fundamental para as cuidadoras. Observou-se que as cuidadoras somente compreendem o caráter progressivo da doença que vai tornando o idoso cada vez mais dependente a partir de sua vivência de cuidado. Essa rede de orientação é essencial para que a família e as cuidadoras realizem o cuidado de forma adequada às necessidades do idoso.

No que trata do Serviço Social, percebe-se que devem ser aprofundados os estudos e pesquisas relativos ao envelhecimento e às novas demandas profissionais, 
assim como ao processo de trabalho nesse contexto, em particular de orientação e suporte às famílias e cuidadoras.

Considera-se, portanto, que a presente pesquisa percebeu a importância do tratamento à Doença de Alzheimer ir além do idoso e inserir também a figura da cuidadora. Essa realidade apresenta impacto no tema das políticas de envelhecimentos e exige discussões sobre o papel das cuidadoras na sociedade, uma vez que casos de dependência, não se restringem à velhice, mas ocorrem em vários momentos da vida. Trata-se, portanto, de uma demanda de justiça social que tem deixado um problema da esfera pública sob responsabilidade apenas das famílias, evidenciado na ausência de políticas públicas para as necessidades das cuidadoras. 


\section{Referências bibliográficas}

ARGIMON, Irani de Lima; TRENTINI, Clarissa Marceli. A presença da doença de Alzheimer e suas repercussões na dinâmica familiar. Revista Brasileira de Ciências do Envelhecimento Humano, Passo Fundo, 2006.

ATTIAS-DONFUT, Claudine. Sexo e envelhecimento. In: PEIXOTO, Clarice Ehlers (org). Família e envelhecimento. Rio de Janeiro: Editora FGV, 2004.

BARROS, Myriam Moraes Lins de. Velhice na contemporaneidade. In: PEIXOTO, Clarice Ehlers (org). Família e envelhecimento. Rio de Janeiro: Editora FGV, 2004.

BEAUVOIR, Simone de. A velhice. Rio de Janeiro: Nova Fronteira, 1990.

BELTRÃO, Kairô Iwakami; CAMARANO, Ana Amélia; KANSO, Solange. Texto para discussão $n^{\circ}$ 1034: Dinâmica populacional brasileira na virada do século XX. Rio de Janeiro: IPEA, 2004.

BORGES. Maria Claudia Moura. O idoso e as políticas públicas e sociais no Brasil. In SIMSON, Olga; NERI, Anita Liberalesso; CACHIONI, Meire. As múltiplas faces da velhice no Brasil. $2^{a}$ ed. Campinas SP: Alínea Editora, 2006.

BRASIL. Resolução CNS $\mathbf{n}^{0}$ 218, de 6 de março de 1997. Disponível em: http://www.datasus.gov.br/conselho/resol97/res21897.htm. Acesso em: 25 novembro 2007.

Ministério da Saúde. Redes estaduais de atenção à saúde do idoso: guia operacional e portarias relacionadas. Brasília: Editora Ministério da Saúde, 2002.

Estatuto do Idoso. Lei 10741/2003 que dispõe sobre o Estatuto do Idoso. Brasília: Senado Federal; Câmara dos Deputados, 2003.

Constituição Federal 1988. Brasília: Senado Federal, 2004.

Ministério da Saúde. Secretaria de atenção à saúde. Departamento de atenção básica. Cadernos de atenção básica $n^{0} 19$. Envelhecimento e saúde da pessoa idosa. Brasília: Ministério da Saúde, 2006.

BRUNO, Marta Regina Pastor. Cidadania não tem idade. Revista Serviço Social e Sociedade. Ano XXIV, nº 75. São Paulo: Editora Cortez, 2003.

BULLA, Leonia Capaverde et al. Familiares de idosos com Alzheimer: Qualidade de vida e redes de apoio social. In: Anais do IX ENPESS - Encontro Nacional de Pesquisadores em Serviço Social. 30 de novembro a 03 de dezembro de 2004 PUCRS. Associação Brasileira de Ensino e Pesquisa em Serviço Social. 
CALDAS, Célia Pereira. O idoso em processo de demência: o impacto na família. In: MINAYO, Maria Cecília de Souza (Org). Antropologia, saúde e envelhecimento. Rio de Janeiro: FIOCRUZ, 2002.

CAMARANO. Ana Amélia (coord). Texto para discussão nº 681: Como vai o idoso brasileiro? Rio de Janeiro: IPEA, 1999.

CAMARANO, Ana Amélia; KANSO, Solange; MELLO, Juliana Leitão e. Como vive o idoso brasileiro? CAMARANO, Ana Amélia (org). Os novos idosos brasileiros: Muito além dos 60? Rio de Janeiro: IPEA, 2004

CAMARANO, Ana Amélia et al. Idosos brasileiros: indicadores de condições de vida e de acompanhamento de políticas. Brasília: Presidência da República, Subsecretaria de Direitos Humanos, 2005.

CARAMELLI, Paulo; BARBOSA, Maira Tonidandel. Como diagnosticar as quatro causas mais freqüentes de demência?. Revista Brasileira de Psiquiatria: São Paulo, 2007. Disponível em: <http://www.scielo.br/scielo.php?script=sci_arttext\&pid=S1516$44462002000500003 \& \operatorname{lng}=p t \& n r m=i s o>$. Acesso em: 04 novembro 2007.

COMBESSIE, Jean-Claude. O método em sociologia. São. Paulo: Edições Loyola, 2004.

COSTA, Sérgio. Bioética e terceira idade. In COSTA, Sérgio; FONTES, Malu; SQUINCA, Flávia (orgs). Tópicos em bioética. Brasília: Letras Livres, 2006.

COSTA, Neidil Espinola da; MENDONÇA, Jurilza Maria; ABIGALIL, Albamaria. Políticas de assistência ao idoso: a construção da Política Nacional de Atenção à Pessoa Idosa no Brasil. In: FREITAS, Elizabete Viana et al (Org.). Tratado de geriatria e gerontologia. Rio de Janeiro: Guanabara Koogan, 2002.

CRESWELL, John W. Projeto de pesquisa: métodos qualitativos, quantitativos e misto. Porto Alegre: Artmed, 2007.

DINIZ, Debora. O que é deficiência. São Paulo: Brasiliense, 2007.

DINIZ, Debora. A Velhice. Revista E - Em Pauta. São Paulo, dezembro, 2006.

FALCÃO, Deusivania Vieira da Silva. Doença de Alzheimer: um estudo sobre o papel das filhas cuidadoras e suas relações familiares. Brasília: Universidade de Brasília - Tese de doutorado, 2006.

GIACOMIN, Karla; UCHOA, Elizabeth; LIMA-COSTA, Maria Fernanda. Projeto Bambuí: a experiência do cuidado domiciliário por esposas de idosos dependentes. Cadernos de Saúde Pública: Rio de Janeiro, v. 21, n. 5, 2005. Disponível em: $<$ http://www.scielosp.org/scielo.php?script=sci_arttext\&pid=S0102-

311X2005000500024\&lng=en\&nrm=iso>. Acesso em: 30 outubro 2007. 
GOMES, Gisele de Cássia; DIOGO, Maria José D’Elboux. Função motora, capacidade funcional e sua avaliação em idosos. In: DIOGO, Maria José D’Élboux, NERI, Anita Liberalesso e CACHIONI, Meire (org). Saúde e qualidade de vida na velhice. $2^{\mathrm{a}}$ ed. Campinas SP: Alínea Editora, 2006.

GUIMARÃES, Iraci Gonçalves. Quando esquecer é o problema: representações sociais de familiares sobre saúde mental no envelhecimento e os desafios impostos pela demência. Brasília: Universidade de Brasília - Dissertação de mestrado, 2005.

HERRERA JUNIOR, Emilio; CARAMELLI, Paulo; NITRINI, Ricardo. Estudo epidemiológico populacional de demência na cidade de Catanduva. Estado de São Paulo, Brasil. Revista de Psiquiatria Clínica, 1998. Disponível em: http://www.hcnet.usp.br/ipq/revista/r252/arti252a.htm. Acesso em: 05 junho 2007.

KARSCH, Ursula M. Cuidadores familiares de idosos: parceiros da equipe de saúde. Serviço Social e sociedade, São Paulo, v. 75: Editora Cortez, 2003a.

Idosos dependentes: famílias e cuidadores. Cadernos de Saúde

Pública: Rio de Janeiro, v. 19, n. 3, 2003b. Disponível em:

$<$ http://www.scielosp.org/scielo.php?script=sci_arttext\&pid=S0102-

311X2003000300019\&lng=en\&nrm=iso >. Acesso em: 30 outubro 2007.

LAVILLE, Christian; DIONNE, Jean. A construção do conhecimento. Porto Alegre: Editora Artes Médicas Sul Ltda; Belo Horizonte: Editora UFMG, 1999.

LEMOS, Naira; MEDEIROS, Sônia Lima. Suporte social ao idoso dependente. In: FREITAS, Elizabete Viana et al (Org.). Tratado de geriatria e gerontologia. Rio de Janeiro: Guanabara Koogan, 2002.

LOBATO, Alzira Tereza Garcia. Serviço social e envelhecimento: perspectivas de trabalho do assistente social na área da saúde. In: BRAVO, Maria Inês Souza et al (org). Saúde e serviço social. São Paulo: Cortez; Rio de Janeiro: UERJ, 2006.

MACHADO, João Carlos Barbosa. Doença de Alzheimer. In: FREITAS, Elizabete Viana et al (org.). Tratado de geriatria e gerontologia. Rio de Janeiro: Guanabara Koogan, 2002.

MAFFIOLETTI, Virgínia Lúcia Reis; LOYOLA, Cristina Maria Douat; NIGRI, Fortunée. Os sentidos e destinos do cuidar na preparação dos cuidadores de idosos. Ciência e saúde coletiva: Rio de Janeiro, v. 11, n. 4, 2006. Disponível em: $<$ http://www.scielosp.org/scielo.php?script=sci_arttext\&pid=S1413-

81232006000400029\&lng=en\&nrm=iso>. Acesso em: 30 outubro 2007.

MEDEIROS, Marcelo; DINIZ, Debora. Envelhecimento e deficiência. Série Anis 36. Brasília: LetrasLivres, 1-8, junho, 2004.

MINAYO, Maria Cecília de Souza. O desafio do conhecimento: Pesquisa qualitativa em saúde. $4^{\text {a }}$ ed. São Paulo; Rio de Janeiro, HUCITEC, ABRASCO, 1996. 
MOSCA FILHO, Mário. Ética e terceira idade. In: SEGRE. Marco (org). A questão ética e a saúde humana. São Paulo: Editora Atheneu, 2006.

NERI, Anita Liberalesso. Biomedicalização da velhice: distorções cognitivas relacionadas ao uso do modelo biomédico na pesquisa gerontológica. In: DIOGO, Maria José D’Élboux; NERI, Anita Liberalesso; CACHIONI, Meire (org). Saúde e qualidade de vida na velhice. $2^{\text {a }}$ ed. Campinas SP: Alínea Editora, 2006.

NERI, Anita Liberalesso; SOMMERHALDER, Cinara. As várias faces do cuidado e do bem-estar do cuidador. In: NERI, Anita Liberalesso (org). Cuidar do idoso no contexto da família: questões psicológicas e sociais. Campinas, SP: Editora Alínea, 2002.

NERI, Anita Liberalesso; CARVALHO, Virgínia Ângela de Lucena e. O bem-estar do cuidador: aspectos psicossociais. In: FREITAS, Elizabete Viana et al (Org.). Tratado de geriatria e gerontologia. Rio de Janeiro: Guanabara Koogan, 2002.

ORGANIZAÇÃO DAS NAÇÕES UNIDAS (ONU). Plano de ação internacional sobre o envelhecimento. Brasília: Secretaria Especial dos Direitos Humanos, 2003.

PEREIRA, Potyara Pereira. Política social, cidadania e neoliberalismo: reflexão sobre a experiência brasileira. In: CARVALHO, Denise Bomtempo Birche de et al (org). Novos paradigmas da política social. Brasília: Universidade de Brasília, Programa de Pós-graduação em política social, Departamento de Serviço Social, 2002.

RAMOS, Luiz Roberto. Epidemiologia do envelhecimento. In: FREITAS, Elizabete Viana et al (Org.). Tratado de geriatria e gerontologia. Rio de Janeiro: Guanabara Koogan, 2002.

RUMEL, Davi et al. Condições de saúde da população brasileira. In: Medicina Ambulatorial: fundamentos e práticas em atenção primária à saúde. Porto Alegre: Artmed, 2004.

SANTOS, Geraldine Alves dos Santos. Os conceitos de saúde e doença na representação social da velhice. Revista Virtual Textos e Contextos: Porto Alegre, v. I, nov. 2002. Disponível em:

$<$ http://www.pucrs.br/textos/anteriores/ano1/gerontologia02.pdf $>$. Acesso em: $10 \mathrm{de}$ julho de 2007.

SANTOS, Maria Azevedo dos Santos; RIFIOTIS, Theophilos. Cuidadores familiares de idosos dementados: uma reflexão sobre o cuidado e o papel dos conflitos na dinâmica da família cuidadora. In: SIMSON, Olga Rodrigues de Moraes Von; NERI, Anita Liberalesso; CACHIONI, Meire (Org). As múltiplas faces da velhice no Brasil. $2^{\mathrm{a}}$ ed. Campinas: Editora Alínea, 2006.

SILVEIRA, Teresinha Mello da; CALDAS, Célia Pereira; CARNEIRO, Terezinha Cuidando de idosos altamente dependentes na comunidade: um estudo sobre cuidadores 
familiares. Cadernos de Saúde Pública: Rio de Janeiro, v. 22, n. 8, 2006. Disponível em: $<$ http://www.scielosp.org/scielo.php?script=sci_arttext\&pid=S0102-

311X2006000800011\&lng=en\&nrm=iso>. Acesso em: 30 outubro 2007

TORRES, Stella Vidal de Souza; SÉ, Elisandra Villela Gasparetto; QUEROZ, Nelma Caires. Fragilidade, dependência e cuidado: desafios ao bem-estar dos idosos e de suas famílias. In: DIOGO, Maria José D’Élboux, NERI, Anita Liberalesso e CACHIONI, Meire (Org). Saúde e qualidade de vida na velhice. $2^{\mathrm{a}}$ ed. Alínea Editora. Campinas, SP, 2006.

VERAS, Renato. A longevidade da população: desafios e conquistas. Revista Serviço Social e Sociedade. Ano XXIV, nº 75. São Paulo: Editora Cortez, 2003.

\section{Filme:}

CLARITA. Direção de Tereza Jessouroun. Rio de Janeiro, 2006. 14 min. DVD, son, color. Áudio português. Documentário, 35 mm. 


\section{ROTEIRO SEMI-ESTRUTURADO PARA ENTREVISTA}

\section{PERFIL DA CUIDADORA}

Idade: anos

Sexo: ( ) feminino ( ) masculino

Última série que completou:

Profissão:

Religião:

Local da residência:

Estado civil:

Parentesco: ( ) filho/filha

( ) esposo/esposa

( ) irmã/irmão

( ) neto/neta

( ) outro:

\section{PERFIL DO IDOSO}

Idade: anos

Sexo: ( ) feminino ( ) masculino

Com quem o idoso reside?

\section{INFORMAÇÕES SOBRE CUIDADO}

1. Por que a família procurou atendimento médico para o idoso?

2. Quando começou o tratamento no Hospital Universitário de Brasília?

3. Qual o diagnóstico de saúde do idoso?

4. O que você sabe sobre essa doença?

5. Como era o seu relacionamento com o idoso antes da doença? 
6. Como é o seu relacionamento com o idoso atualmente?

7. Como é a sua rotina?

8. Quem é o cuidador principal?

9. Outros membros da família colaboram com o cuidado?

10. Existe algum cuidador contratado?

11. Para você, o que é cuidar?

12. Quais são as principais dificuldades no cuidado com o idoso?

13. Você tem orientações sobre como cuidar do idoso? 


\section{Centro de Medicina do Idoso HUB-UnB}

Centro de Referência para os Portadores da Doença de Alzheimer

Memo 28/2007

Brasilia, 19 de julho de 2007.

DO: $\mathrm{CM}$

Ao: IHD/Depto. De Serviço Social

Assunto: Monografia

Senhor Chefe,

O projeto de monografia apresentado por THAIS KRISTOSCH IMPERATORI atende às boas normas científicas e é coerente com as atividades desenvolvidas neste Centro.

Opino favoravelmente à sua realização, comprometendo-me a apoiar a estudante durante a sua permanência nesta Unidade.

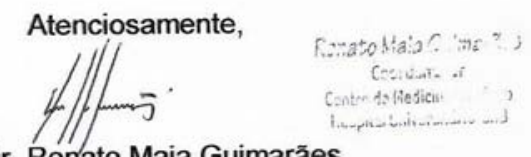

Dr. Renato Maia Guimarães

Coordenador do Centro de Medicina do Idoso 